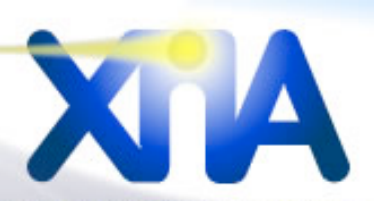

Instruments that advance the art

\title{
High Rate X-ray Fluorescence Detector
}

\author{
Final Technical Report for \\ DOE Grant DE-FG02-06ER84407
}

\begin{tabular}{|l|l|}
\hline Grant Recipient & XIA LLC \\
\hline Grantee Address & $\begin{array}{l}\text { 31057 Genstar Rd. } \\
\text { Hayward, CA 94544 }\end{array}$ \\
\hline Principal Investigator & Dr. Peter Grudberg \\
\hline Date of Report & $4 / 30 / 13$ \\
\hline
\end{tabular}

\section{SBIR/STTR RIGHTS NOTICE}

These SBIR/STTR data are furnished with SBIR/STTR rights under Grant No. DE-FG02-06ER84407. For a period of four (4) years after acceptance of all items to be delivered under this grant, the Government agrees to use these data for Government purposes only, and they shall not be disclosed outside the Government (including disclosure for procurement purposes) during such period without permission of the grantee, except that, subject to the foregoing use and disclosure prohibitions, such data may be disclosed for use by support contractors. After the aforesaid four-year period, the Government has a royalty-free license to use, and to authorize others to use on its behalf, these data for Government purposes, but is relieved of all disclosure prohibitions and assumes no liability for unauthorized use of these data by third parties. This Notice shall be affixed to any reproductions of these data in whole or in part. 


\section{Table of Contents}

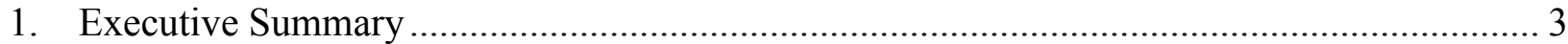

2. A Comparison of Actual Accomplishments with Project Technical Objectives ...................... 4

3. Detailed Project Activities .......................................................................................... 7

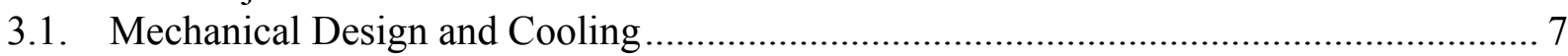

3.2. Investigation of detector geometry and preamplifier signal rise times.......................... 12

3.2.1. Relative intensity: defining the detector element boundaries .....................................................13

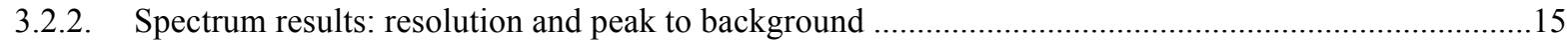

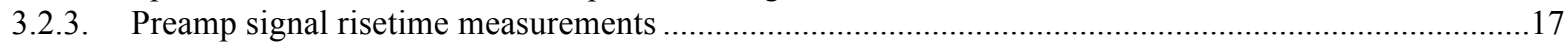

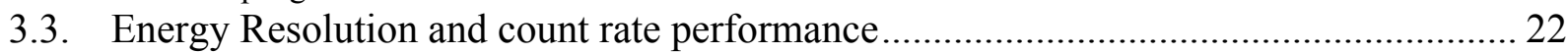

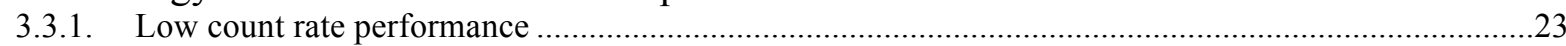

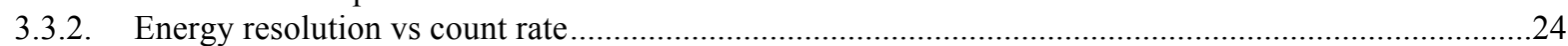

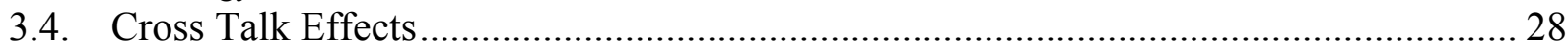




\section{Executive Summary}

The purpose of this project was to develop a compact, modular multi-channel x-ray detector with integrated electronics. This detector, based upon emerging silicon drift detector (SDD) technology, will be capable of high data rate operation superior to the current state of the art offered by high purity germanium (HPGe) detectors, without the need for liquid nitrogen. In addition, by integrating the processing electronics inside the detector housing, the detector performance will be much less affected by the typically noisy electrical environment of a synchrotron hutch, and will also be much more compact than current systems, which can include a detector involving a large LN2 dewar and multiple racks of electronics. The combined detector/processor system is designed to match or exceed the performance and features of currently available detector systems, at a lower cost and with more ease of use due to the small size of the detector. In addition, the detector system is designed to be modular, so a small system might just have one detector module, while a larger system can have many - you can start with one detector module, and add more as needs grow and budget allows. The modular nature also serves to simplify repair.

In large part, we were successful in achieving our goals. We did develop a very high performance, large area multi-channel SDD detector, packaged with all associated electronics, which is easy to use and requires minimal external support (a simple power supply module and a closed-loop water cooling system). However, we did fall short of some of our stated goals. We had intended to base the detector on modular, large-area detectors from Ketek GmbH in Munich, Germany; however, these were not available in a suitable time frame for this project, so we worked instead with pnDetector $\mathrm{GmbH}$ (also located in Munich). They were able to provide a front-end detector module with six $100 \mathrm{~m}^{\wedge} 2$ SDD detectors (two monolithic arrays of three elements each) along with associated preamplifiers; these detectors surpassed the performance we expected to get from the Ketek detectors, however they are housed in a sealed module, which does not offer the ease of repair and expandability we'd hoped to achieve with the Ketek SDD's. Our packaging efforts were quite successful, as we came up with a very compact way to mount the detector and to house the associated electronics, as well as a very effective way to reliably take out the heat (from the electronics as well as the detector's Peltier coolers) without risk of condensation and without external airflow or vibration, which could create problems for the target applications. While we were able to design compact processing electronics that fit into the detector assembly, they are still at the prototype stage, and would require a significant redesign to achieve product status.

We have not yet tested this detector at a synchrotron facility; we do still plan on working with some close contacts at the nearby Stanford Synchrotron Radiation Laboratory (SSRL) to get some testing with the beam (using existing commercial electronics for readout, as the integrated processor is not ready for use). 


\section{A Comparison of Actual Accomplishments with Project Technical Objectives}

Below are the technical objectives described in the Phase II proposal and a summary of accomplishments for each objective.

\begin{tabular}{|c|c|}
\hline Project Technical Objectives & $\begin{array}{r}\text { Actual Accomplishments } \\
\end{array}$ \\
\hline $\begin{array}{l}\text { Objective 1: Develop the } \\
\text { detector module }\end{array}$ & $\begin{array}{l}\text { The hexagonal Ketek detectors were not available for this project, } \\
\text { so we followed an alternative path using large-area monolithic } \\
\text { detectors from pnDetector. Ultimately, the final encapsulated } \\
\text { module and associated preamplifier/detector support electronics } \\
\text { did a good job in meeting this objective. }\end{array}$ \\
\hline $\begin{array}{l}\text { Task 1: Acquire detectors and } \\
\text { develop detector mounting plate }\end{array}$ & $\begin{array}{l}\text { After determining the Ketek Hex modules were not available, we } \\
\text { worked wit pnDetector to specify a custom large area detector, } \\
\text { incorporating two three-element monolithic detectors; each } \\
\text { detector element is nominally } 100 \mathrm{~mm}^{\wedge} 2 \text {. The detector module } \\
\text { incorporates the appropriate mounting plate. }\end{array}$ \\
\hline Task 2: Develop cooling system & $\begin{array}{l}\text { To achieve the target performance, the SDD detector must be } \\
\text { cooled; in addition, the heat from the processing electronics must } \\
\text { be removed from the system. The detector module incorporates a } \\
\text { two-stage Peltoer cooler that can achieve a } 50 \text { degrees centigrade } \\
\text { temperature differential; the detector module is backed by two } \\
\text { large copper cooling blocks. Our goal was to maintain those } \\
\text { blocks at room temperature (further cooling runs the risk of } \\
\text { condensation). } \\
\text { After studying and simulating several possibilities, we decided } \\
\text { upon a water cooling system to both take the heat from the Peltier } \\
\text { coolers as well as the processing electronics; this system turned } \\
\text { out to be quite reliable and easy to use. }\end{array}$ \\
\hline $\begin{array}{l}\text { Task 3: Design power and bias } \\
\text { supply system }\end{array}$ & $\begin{array}{l}\text { This task was simplified by the fact that the front-end detector } \\
\text { processing electronics - preamplifiers and power supply boards - } \\
\text { were provided along with the detector module. We just had to } \\
\text { supply appropriate power supply voltages; the voltage outputs } \\
\text { from the detector support boards were pre-tuned for optimal } \\
\text { performance prior to delivery to us. }\end{array}$ \\
\hline $\begin{array}{l}\text { Task 4: Design and fabricate } \\
\text { detector head enclosure }\end{array}$ & $\begin{array}{l}\text { The detector was provided as a sealed enclosure with a beryllium } \\
\text { window, so no additional work was necessary. We did develop a } \\
\text { nose piece to go over the detector module to help seal the overall } \\
\text { assembly and provide protection. }\end{array}$ \\
\hline $\begin{array}{l}\text { Task 5: Evaluate detector } \\
\text { performance with DXP-xMAP } \\
\text { system }\end{array}$ & $\begin{array}{l}\text { The detectors work quote well with the xMAP electronics, } \\
\text { achieving consistent results between all six channels, and } \\
\text { exceeding the performance of most similar detectors. }\end{array}$ \\
\hline $\begin{array}{l}\text { Objective 2: Design and } \\
\text { fabricate the Electronics }\end{array}$ & $\begin{array}{l}\text { The electronics required for this detector can be split into three } \\
\text { parts: preamplifiers, processing electronics and power supply } \\
\text { electronics. } \\
\text { We decided against developing our own preamplifier, and } \\
\text { obtained the preamplifiers as part of the detector module purchase. }\end{array}$ \\
\hline
\end{tabular}




\begin{tabular}{|c|c|}
\hline & $\begin{array}{l}\text { We successfully developed a prototype compact } 8 \text {-channel digital } \\
\text { pulse processor (DPP) assembly, as well as a compact power } \\
\text { supply board designed to provide power to both the DPP and the } \\
\text { preamplifier boards. Finally, we developed an external module } \\
\text { that runs the whole system from a NIM bin. }\end{array}$ \\
\hline Task 6: Select preamplifier design & $\begin{array}{l}\text { We briefly looked into developing our own SDD preamplifier, } \\
\text { either by ourselves or in collaboration; however, this is not our } \\
\text { primary expertise, and all of the third-party designs we saw were } \\
\text { either far too large or otherwise would not fit our application. We } \\
\text { were able to obtain preamplifiers along with our detector module } \\
\text { purchase, as pnDetector did offer a standard preamplifier along } \\
\text { with their detectors. As part of the module purchase, they } \\
\text { developed a compact three-channel preamplifier board and } \\
\text { associated detector support board; two such board pairs are used to } \\
\text { support the detector. }\end{array}$ \\
\hline $\begin{array}{l}\text { Task 7: Design and fabricate } \\
\text { analog signal conditioning } \\
\text { electronics }\end{array}$ & $\begin{array}{l}\text { On our commercial DXP electronics, we use several patented } \\
\text { methods in our analog front end to minimize the dynamic range of } \\
\text { the signal to digitize, which allows us to use cheaper ADC's. One } \\
\text { result of this approach is that the analog circuitry takes up } \\
\text { significant board space. } \\
\text { We decided to take an approach where we combine a single 8- } \\
\text { channel digital processor card with two 4-channel analog cards, } \\
\text { sandwiched together to fit into a small volume. Using three boards } \\
\text { allowed us to take the conservative approach of duplicating the } \\
\text { analog circuitry we use on our commercial xMAP system. }\end{array}$ \\
\hline $\begin{array}{l}\text { Task 8: Design and fabricate } \\
\text { digital processing electronics }\end{array}$ & $\begin{array}{l}\text { We developed a compact 8-channel digitizer card, using the same } \\
\text { basic architecture as our DXP-xMAP and DXP Mercury } \\
\text { commercial products, and taking advantage of the availability of } \\
\text { an 8-channel, 14-but } 50 \mathrm{MHz} \text { ADC. While we verified the basic } \\
\text { performance of the card, we had problems implementing the } \\
\text { serialized LVDS readout employed by the ADC to allow the high } \\
\text { channel density; data from each channel is carried on a single } \\
\text { LVDS pair, which runs at } 700 \mathrm{Mbit} / \mathrm{sec} \text {. For a production version } \\
\text { of this processor, we would switch to a newer FPGA design which } \\
\text { includes explicit deserialization support (we made our FPGA } \\
\text { choice based upon the part used in the ADC development kit). }\end{array}$ \\
\hline $\begin{array}{l}\text { Task 9: Fabricate detector supply } \\
\text { electronics }\end{array}$ & $\begin{array}{l}\text { We developed a compact power supply board that fits within the } \\
\text { detector housing, which takes nominal power supply inputs and } \\
\text { generates both the voltages required by the pulse processing } \\
\text { electronics, the detector support electronics (including } \\
\text { preamplifiers) and the detector Peltier coolers. } \\
\text { In addition, we built a NIM power supply module, which provides } \\
\text { the nominal NIM voltages ( } \pm 6 \mathrm{~V}, \pm 12 \mathrm{~V} \text { and } \pm 24 \mathrm{~V}) \text {, as well as } \\
\text { incorporating two low-noise high voltage supplies to provide the } \\
\text { bias for the two monolithic SDD arrays (up to } 200 \mathrm{~V}) \text {. }\end{array}$ \\
\hline Objective 3: Mechanical design & $\begin{array}{l}\text { We successfully developed a compact housing for the modular } \\
\text { SDD and associated electronics, providing both relatively easy } \\
\text { access to all electronics as well as good cooling performance. }\end{array}$ \\
\hline
\end{tabular}


Task 10: Determine arrangement and functional organization of printed circuit boards outer case and interior framework

Objective 4: Develop the firmware and host control software for the digital pulse processor
Task 11: Design and fabricate

The board arrangements were constrained by the fact that we did not design the preamplifier boards. As a result, we had to use more internal cables than we'd hoped. IN the end, we came up with a reasonable arrangement, where the three processor boards (one digital and two analog) were tightly bound together with board to board connectors, and short cables were used to connect the power board to the processor and the preamplifier assemblies, as well as the preamplifier outputs to the processor boards.

We used angled aluminum to construct a customized space frame to mount all the boards, with the detector module mounted at one end. The entire assembly fits inside a square aluminum tube, 3 inches on each side (outer dimension), and 12 inches long.

The processor we developed is based largely upon our XMAP and Mercury processors, so that we can reuse as much code as possible; the main difference is the serial LVDS ADC inputs, which required very careful firmware development.

The processor never made it beyond prototype status, so we did not do the associated software work (driver, GUI).

The focus of the FPGA code we developed was on deserializing the $700 \mathrm{Mbit} / \mathrm{sec}$ LVDS lines for each of the eight channels. Once the ADC data is parallelized, it is fed into our standard processor firmware.

The deserialization task turned out to be nearly impossible, due to

Task 12: Develop FPGA code for the SeptaHex processor

the fact that the FPGA we chose (a Xilinx Virtex2) did not have dedicated logic for the job (the FPGA was chosen based upon the part that was used on the ADC development kit). We were able to get several channels working at one time, but it was extremely difficult to get all 8 channels to work simultaneously.

If we decide to commercialize this processor, we will update it with a more advanced FPGA.

\begin{tabular}{|l|l|}
\hline $\begin{array}{l}\text { Task 13: Develop USB2 } \\
\text { Microcontroller code }\end{array}$ & $\begin{array}{l}\text { We were able to directly use USB3 code that we developed for our } \\
\text { commercial Mercury spectrometer. }\end{array}$ \\
\hline Task 14: Develop software driver & Not done. \\
\hline $\begin{array}{l}\text { Task 15: Develop graphical user } \\
\text { interface (GUI) }\end{array}$ & $\begin{array}{l}\text { Not done (but our standard GUI would work essentially 'out of the } \\
\text { box' as long as the driver was written). }\end{array}$ \\
\hline $\begin{array}{l}\text { Objective 5: Evaluate the } \\
\text { performance of the prototype } \\
\text { detector }\end{array}$ & $\begin{array}{l}\text { We performed a wide range of tests on the detector, using our } \\
\text { commercial DXP-xMAP processor. }\end{array}$ \\
\hline $\begin{array}{l}\text { Task 16: High rate testing with x- } \\
\text { ray tube source }\end{array}$ & Done, using the xMAP processor. \\
\hline $\begin{array}{l}\text { Task 17: Testing at local } \\
\text { synchrotron sources }\end{array}$ & $\begin{array}{l}\text { Not done, but we intend to bring the detector to SSRL for testing } \\
\text { in the near future. }\end{array}$ \\
\hline $\begin{array}{l}\text { Objective 6: Develop and test } \\
\text { high rate readout system }\end{array}$ & $\begin{array}{l}\text { Not done, as this mainly focused on reading out several detectors, } \\
\text { so this was a low priority. }\end{array}$ \\
\hline
\end{tabular}




\section{Detailed Project Activities}

\subsection{Mechanical Design and Cooling}

Figure 1 is a schematic of the XAS detector housing with the outer case removed. (For clarity, electrical wiring and water cooling tubes are not shown). The 6-element encapsulated SDD was supplied with two copper mounting blocks for removing the heat from the internal Peltier coolers. Each block was screwed to a copper plate, which was mounted on the Aluminum framework by thermally insulating hardware, (nylon screws). The copper plates (and detector mounting blocks) were maintained at a fixed temperature set between $18-20^{\circ} \mathrm{C}$ by a water cooling block supplied from an external water chiller. The internal Peltier coolers provide a temperature difference of about $50^{\circ} \mathrm{C}$, resulting in an SDD operating temperature of about $-30^{\circ}$ $\mathrm{C}$, which is required for optimum energy resolution.

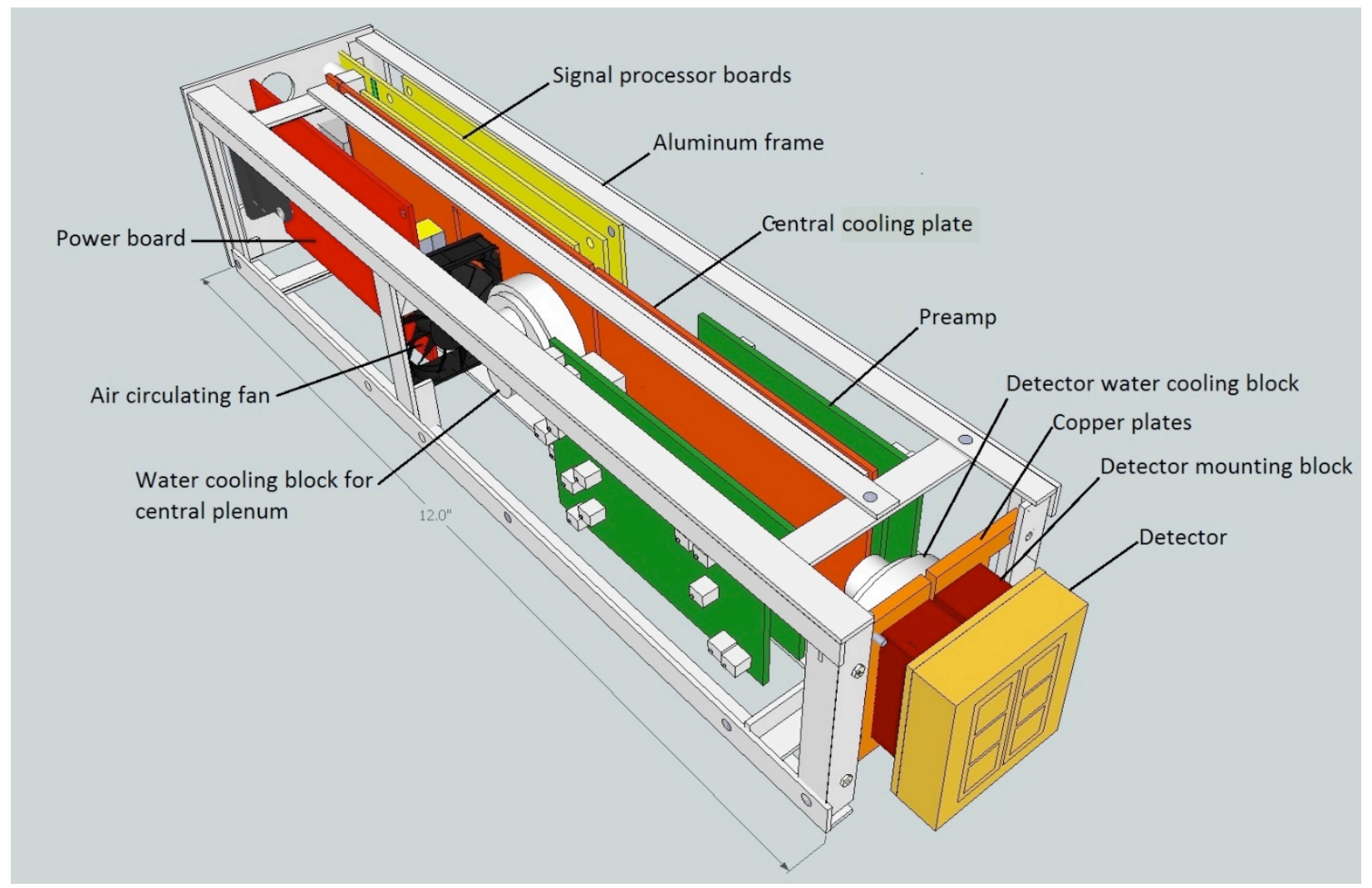

Figure 1: Schematic of the detector housing with outer case removed.

When the outer case and detector nosecone are fitted, (figure 2), the housing formed a (loosely) sealed unit with no air flow to the exterior. Cooling of the electronic boards, (two 3-channel preamplifiers, power board, and signal processor boards), was achieved by the placement of a central copper plate cooled by a second water block. The two water blocks were wired in series with the external water chiller. An internal fan circulated air around the internal components across both sides of the cooled plate; there was a sufficient gap at each end of the plate for air to circulate. Figure 3 is a photograph of the finished detector assembly showing the second water 
block mounted on the copper plate between a preamplifier and the power board. Figure 4 is a view from the other side of the detector and shows the central copper plate more clearly. (In this photograph the processor boards have been removed and the preamplifier is wired for use with an external pulse processor). The efficacy of the air circulation scheme was proved by replacing the outer case with a temporary transparent structure, and introducing visible vapor boiled off from LN. Circulation of the vapor throughout the internal space of the housing could clearly be seen.

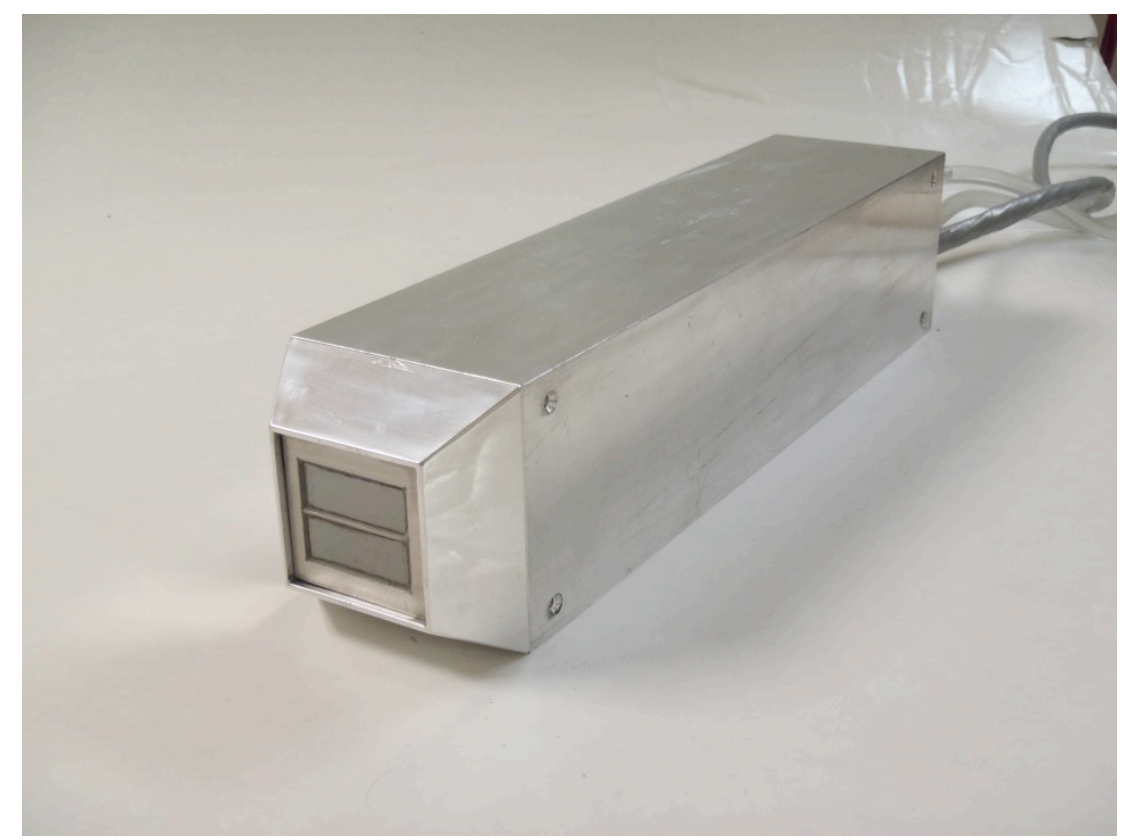

Figure 2: Detector housing with outer case and nosecone fitted.

The two Beryllium windows for the six SDD elements are visible at the front.

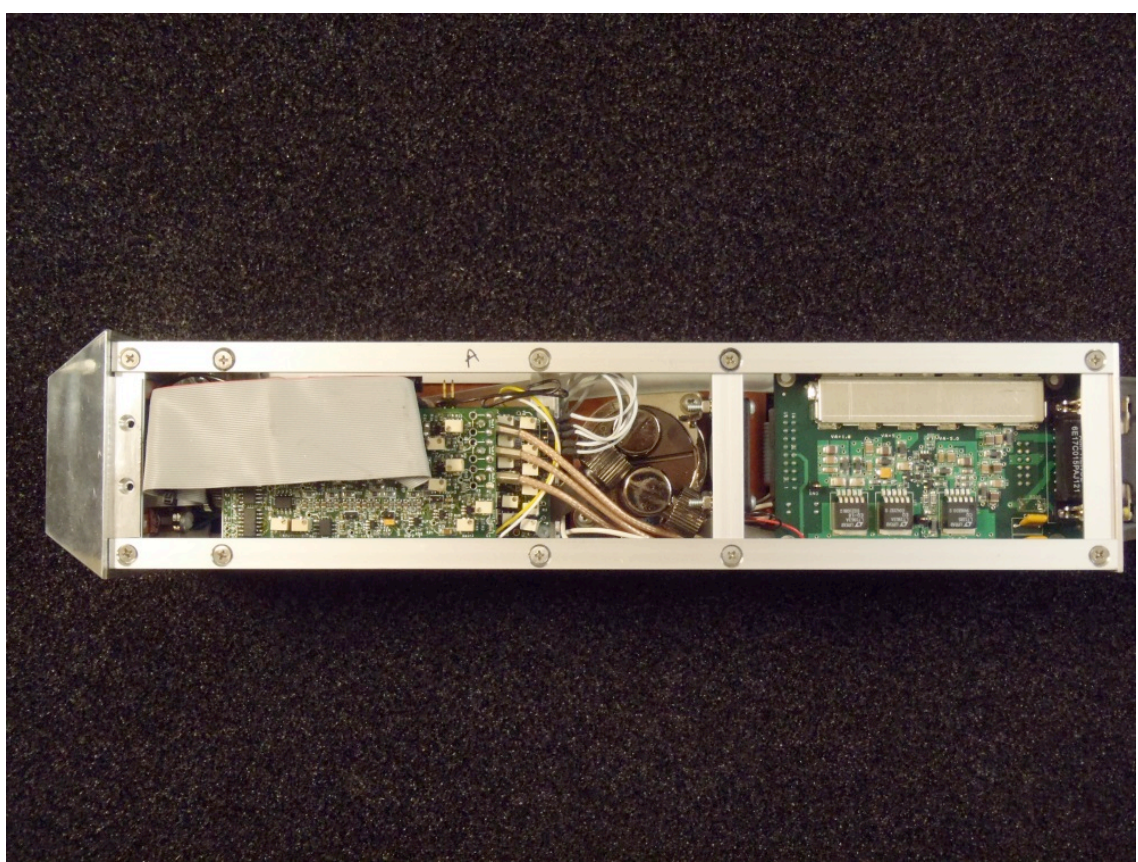

Figure 3: Complete assembly with case removed, showing one of the 3-channel preamplifiers, 
the second water cooling block, and the power board. The ribbon cable connects the preamplifier to the SDD.

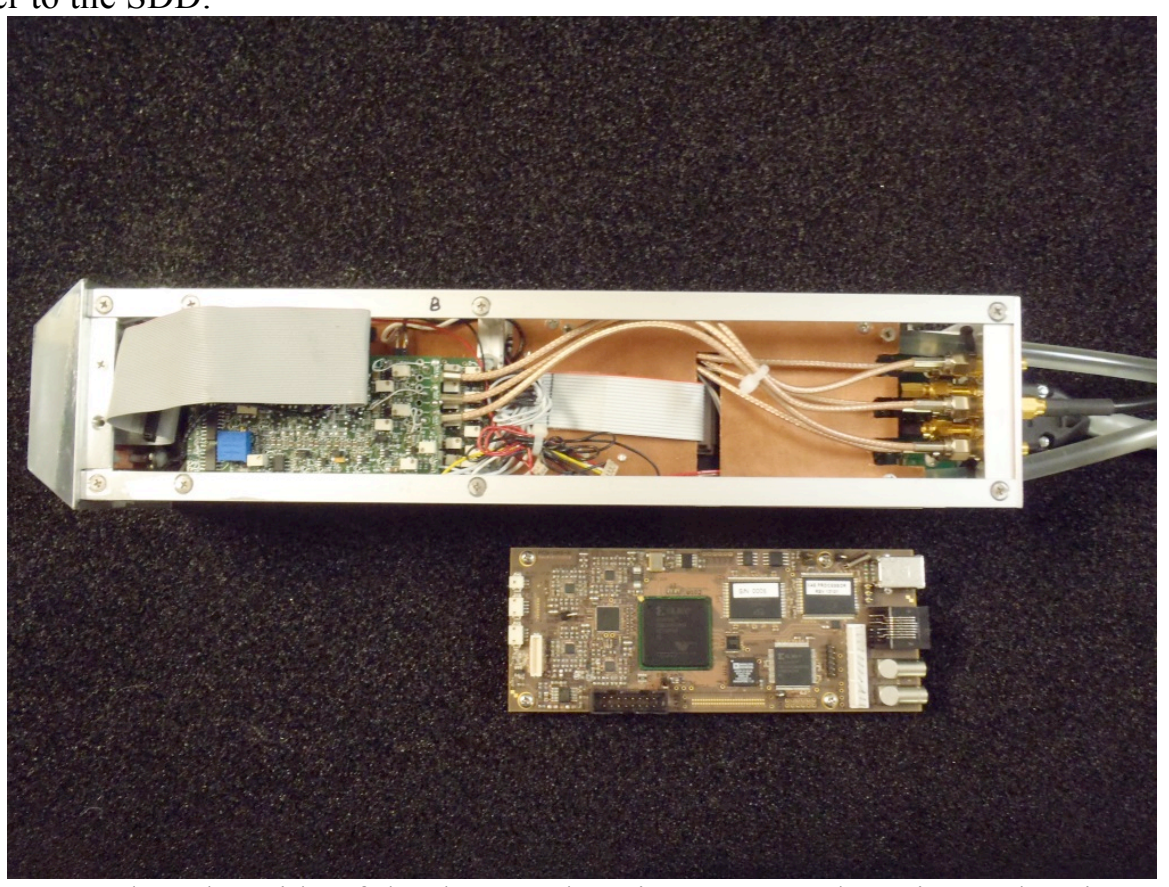

Figure 4: The other side of the detector housing compared to Fig. 3, showing the central copper plate. (The pulse processor boards have been removed, and the preamplifier is wired for an external processor).

\section{Verification of detector cooling method}

$\underline{\text { Initial temperature tests with simulated heat load }}$

Before the detector assembly was completed an initial experiment was performed to check air temperature inside the sealed housing. Heat loads of the power board and processor boards were simulated by gluing $5 \mathrm{Ohm}$ resistors to additional copper plates and mounted off the central cooling plate, (figure 5). The simulated heat loads were $10 \mathrm{~W}$ and $3 \mathrm{~W}$ for the processor and power boards respectively. During the tests the preamplifiers, detector, and Peltier coolers were fully powered to their normal operating level, (12V Peltier voltage, $1.9 \mathrm{~A})$. The water chiller temperature was preset to $20^{\circ} \mathrm{C}$, and room temperature was approximately $24^{\circ} \mathrm{C}$. For the first tests the cooled water flowed through the detector block first and then the block on the central copper plate. The direction of flow was reversed in a second test.

The internal cooling system is designed to work by maintaining the central cooling plate close to $20^{\circ} \mathrm{C}$ while creating a circulating air flow over the cool surface and across the electronic boards. To this end, the initial voltage on the air-circulating fan was set at $12 \mathrm{~V}$, and reduced to $5 \mathrm{~V}$ in a later test.

The internal air temperature was measured by suspending a thermocouple sensor about $1 \mathrm{~cm}$ above the center of the simulated processor board. 


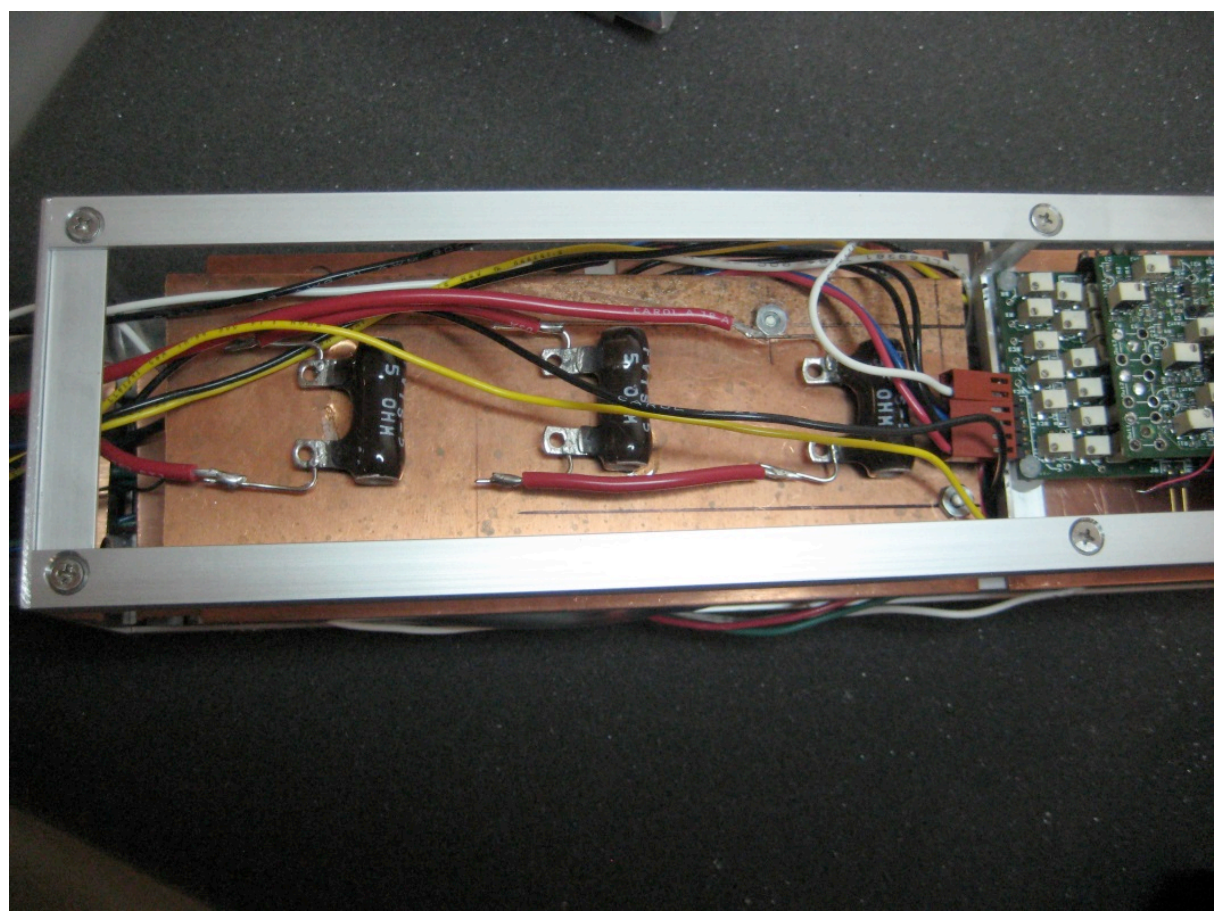

Figure 5: Simulated heat load for analog and processor boards (10W). The resistors were mounted on a separate copper plate raised off the central cooling plate.

Figure 6 shows the change of the internal air temperature with time under various conditions. The first experiment (blue line) was for water flowing through the block on the detector first, and with $12 \mathrm{~V}$ fan voltage. It can be seen that the air temperature stabilized at about $31^{\circ} \mathrm{C}$, which is well in the range of tolerance for the electronic boards. The blue line in figure 7 shows the temperature of one of the detector elements under the same conditions, and is stable with time. After 60 minutes the detector HV and Peltier current was switched off, resulting in a slight decline of the internal temperature, as expected. The water chiller was then turned off; the blue line in figure 6 from 75 minutes onwards shows the rapid increase in the internal temperature resulting from the preamps and the simulated boards only. This test confirmed the effectiveness of the water cooling scheme.

The red lines in figures 6 and 7 show the effect of reversing the water flow so that the coolest water flows to the central copper plate first. As expected, there was a small $\left(0.4^{\circ} \mathrm{C}\right)$ improvement in the air temperature, and about $0.3^{\circ} \mathrm{C}$ increase in detector temperature, neither of which is significant. For the remaining tests the water flow was restored to the original direction.

The green line in figures 6 and 7 shows the effect of air flow when the fan voltage is reduced from $12 \mathrm{~V}$ to $5 \mathrm{~V}$, and then restored to $12 \mathrm{~V}$. The air temperature rose by $2.5^{\circ} \mathrm{C}$ with the slower air speed, and there seemed to be a small $\left(0.3^{\circ} \mathrm{C}\right)$ systematic increase in the detector temperature. $12 \mathrm{~V}$ was chosen as the operating voltage of the fan for all future tests. 


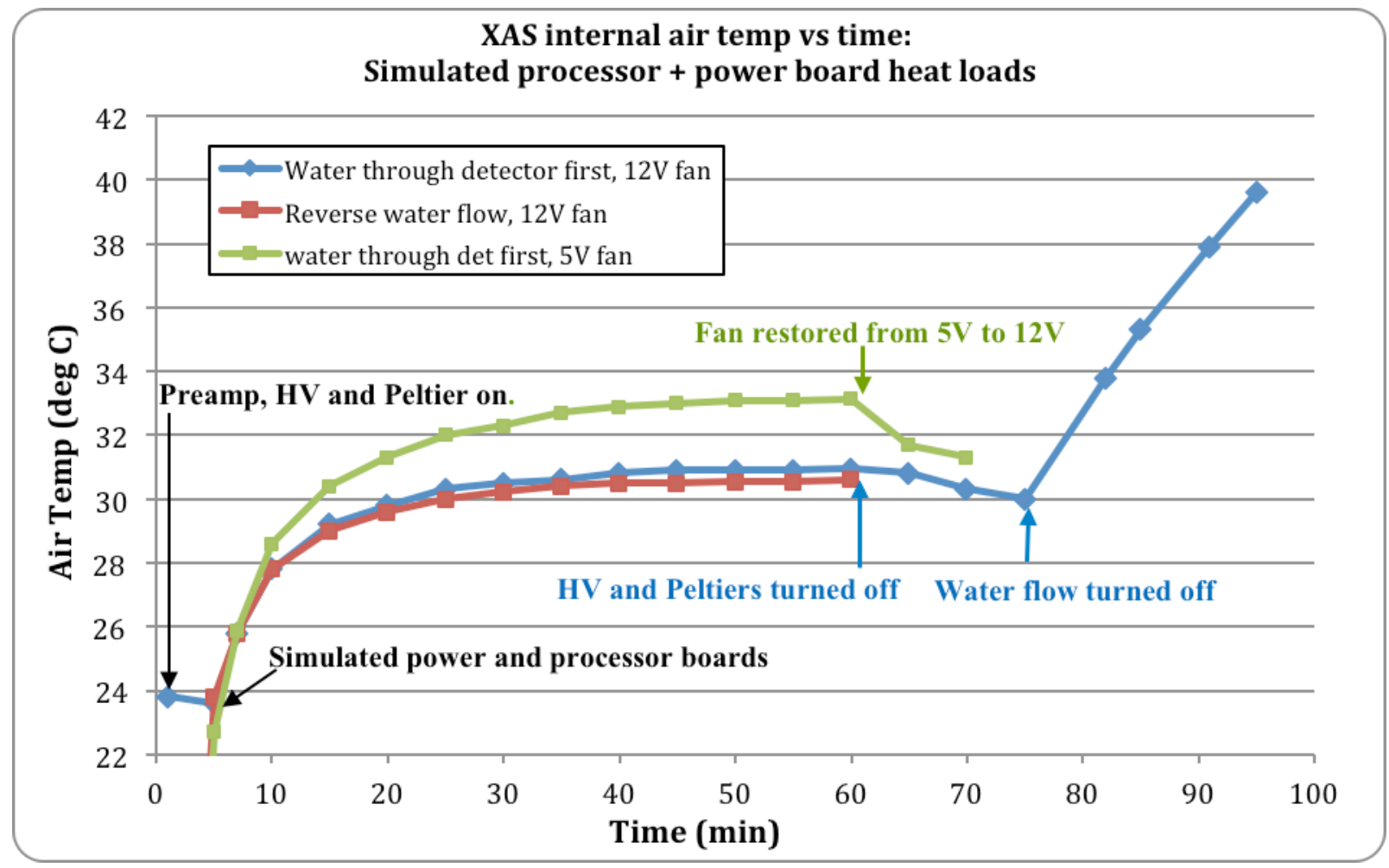

Figure 6. Internal air temperture vs. time, showing the effect of water flow direction, fan speed, and turning the water cooing off.

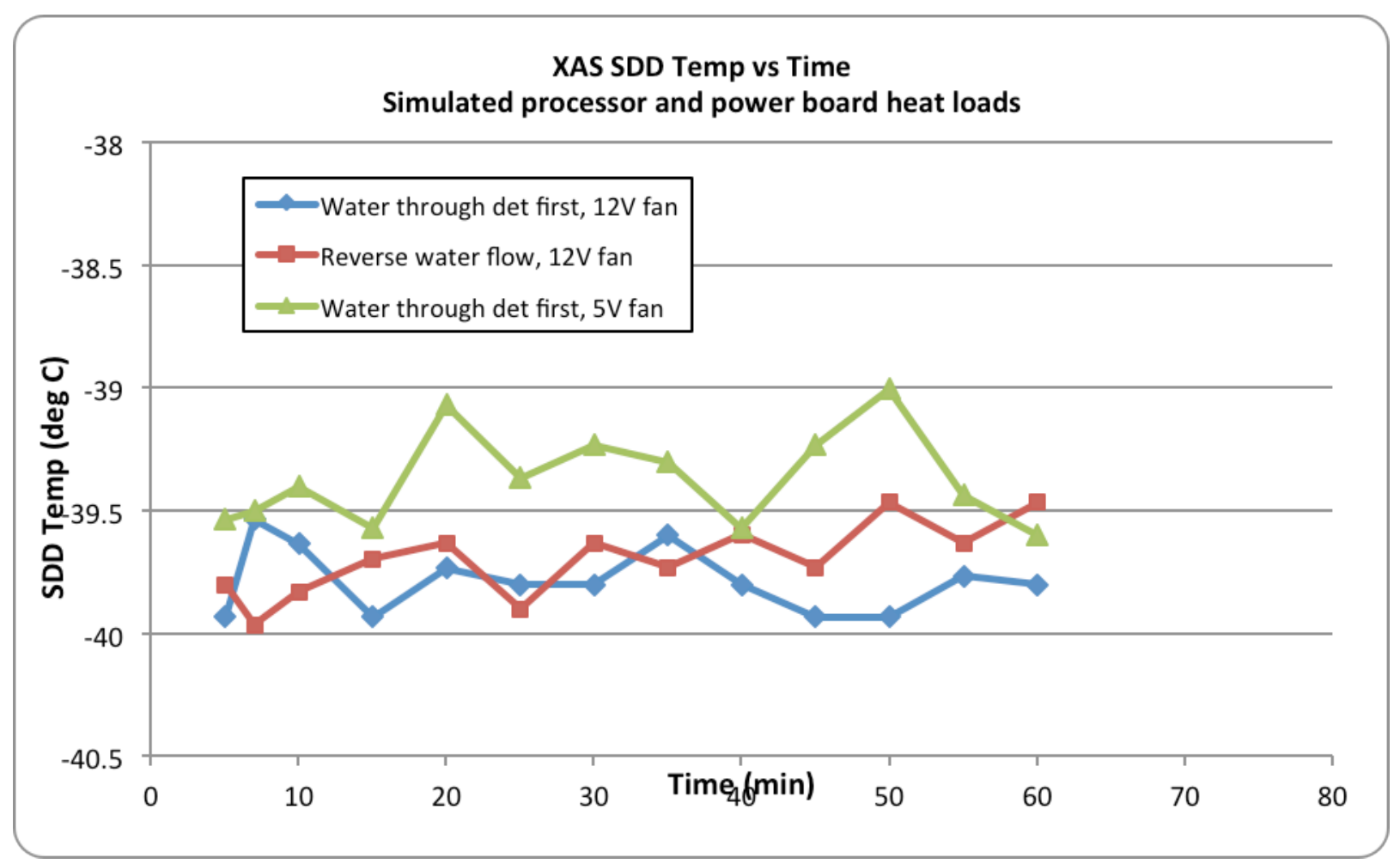

Figure 7. SDD temperature vs time under the same conditions as figure 6. 
The conclusion was that the combined water and air-cooling system in the sealed housing worked well, even with the moderate water temperature $\left(20^{\circ} \mathrm{C}\right)$ used for these measurements. The $31^{\circ} \mathrm{C}$ air temperature indicated spare cooling capacity should the final heat load be somewhat higher than the simulation.

Final temperature tests with processor and power boards

For these measurements the detector was fully assembled with working analog and processor boards. As in the earlier test, the SDD was powered with HV applied; the Peltier current was 2A at $12 \mathrm{~V}$. The water temperature was $20^{\circ} \mathrm{C}$, and the fan voltage set to $12 \mathrm{~V}$.

Figure 8 shows the increase in air temperature inside the box after all components were powered on and the FPGA and DSP firmware files loaded. After about 110 minutes the position of the air temperature probe was inadvertently moved, resulting in a $1^{\circ} \mathrm{C}$ drop of the measured temperature. At about 190 minutes the processor was "exercised" by initiating read/write commands, which increased the power load and caused the air temperature to rise to $28.6^{\circ} \mathrm{C}$. At this peak air temperature, a separate temperature sensor on the processor board measured $36^{\circ} \mathrm{C}$.

The firmware conditions that gave the maximum power load were not well understood at the time of the measurements, and there was some uncertainty as to whether the maximum heat load was being applied. This may explain the lower air temperature in figure 8 compared to the simulation (figure 6). However, both the maximum air temperature and processor board temperatures were well within acceptable limits, (with margin to spare), for both the simulation and with the working boards.

Figure 9 shows measurements from the two temperature sensors internal to the SDD versus time from powering up the Peltier coolers, (same conditions as figure 8). The SDD temperature settled to around $-35^{\circ} \mathrm{C}$ within a few minutes and was stable throughout the course of all the experiments, being only dependent on the water temperature. This is well within the operating limits of the detector, with a $10^{\circ} \mathrm{C}$ safety margin.

It was concluded that the selected cooling method as described above was satisfactory for both the SDD and the associated electronic boards.

\subsection{Investigation of detector geometry and preamplifier signal rise times}

An attempt was made to characterize the rise times of the preamp signals from the $6 \times 100 \mathrm{sqmm}$ SDD. The data was helpful in determining some of the pulse processor operating settings, and could be of use in future work to improve pile-up discrimination. The measurements also defined the active area of the detector elements, and gave the spectrum performance (energy resolution and peak-to-background) for interactions at various points on the detector surface. 
The SDD was irradiated with an X-ray tube and Mn sample, which was capable of producing count rates in excess of 1 Mcps.. Huber slits formed a 1 sq.mm collimator that was scanned across the surface of the detector in $1 \mathrm{~mm}$ steps. At each step a spectrum was collected, the count rate (intensity) recorded, and several traces stored on the digital oscilloscope for rise time analysis. Two detector elements (approx 100 sq.mm each) were scanned in the vertical direction, and one in the horizontal direction. Figure 10 shows the approximate position of each horizontal and vertical step.
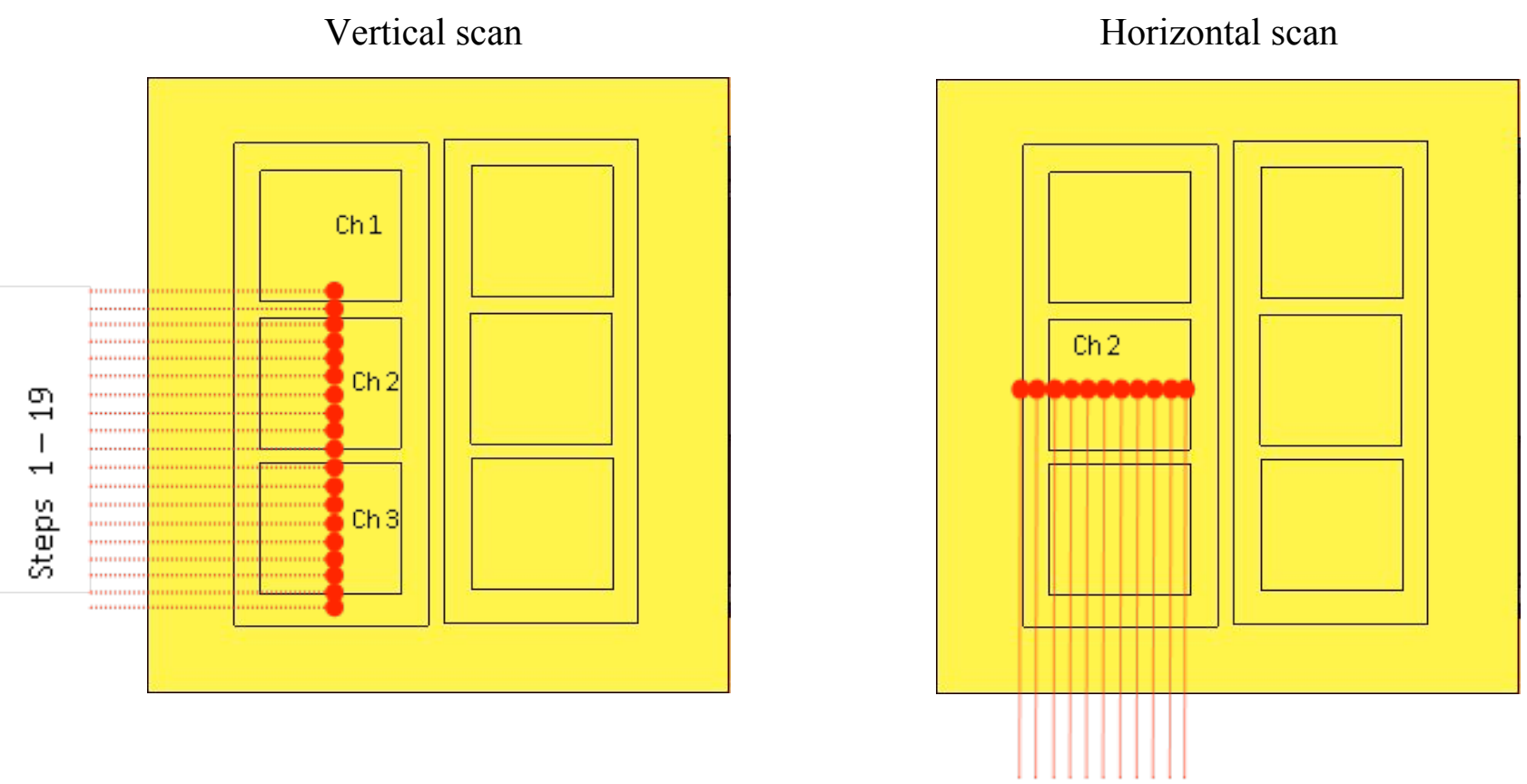

Steps 1-11

Figure 10: Approximate position of collimator hole for each step.

\subsubsection{Relative intensity: defining the detector element boundaries}

Figure 11 shows the relative intensity (count rate) in three detector elements (designated ch $1,2 \& 3$ ), as the source was scanned in the vertical direction. 


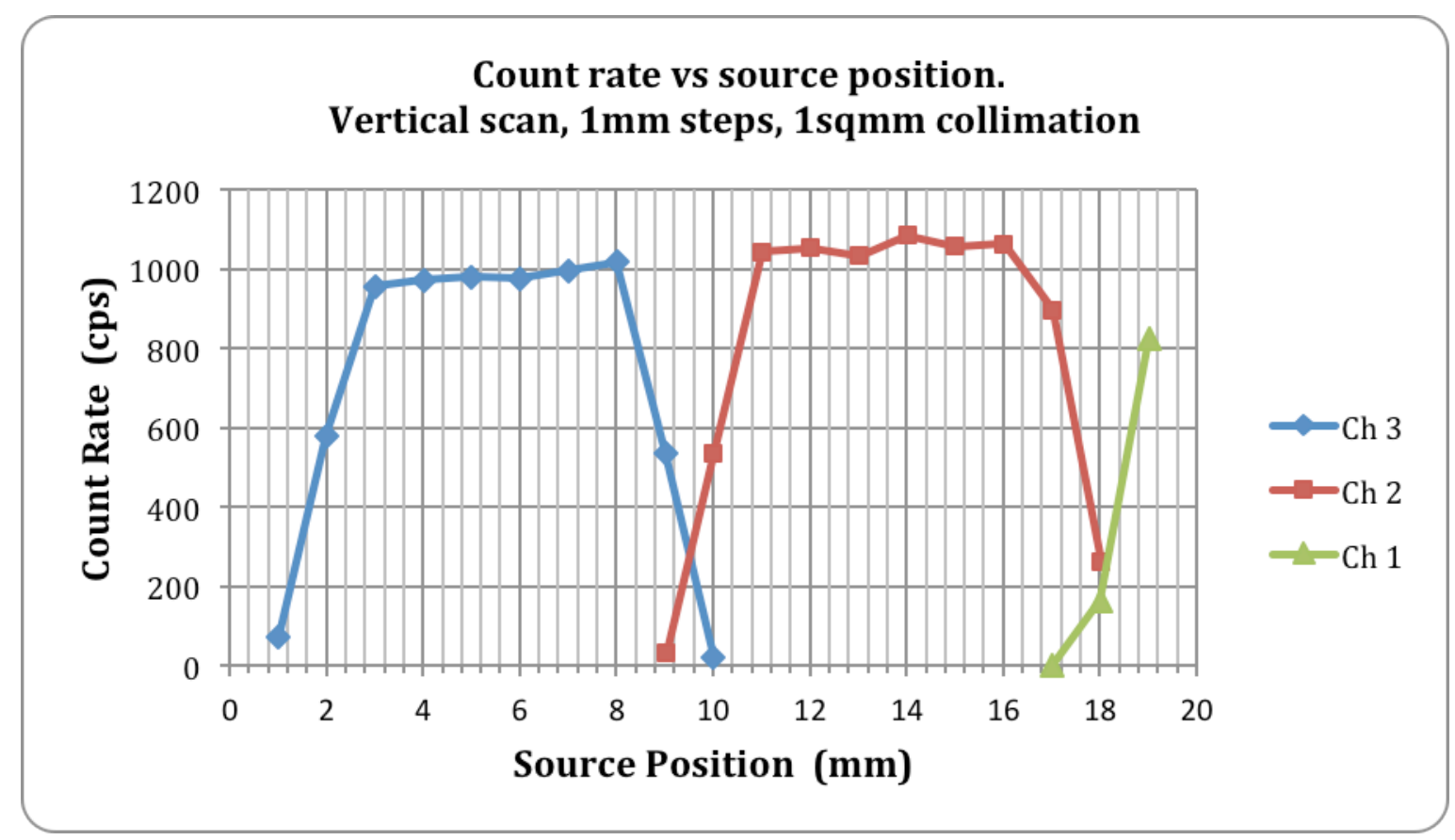

Figure 11. Collection efficiency in the vertical direction.

Figure 12 shows the variation of collection efficency for a scan in the horizontal direction for channel \#2, (middle detector). The SDD assembly has an internal collimator that defines the active area, but note that the detector elements are not square, but are slightly broader in the "horizontal" direction.

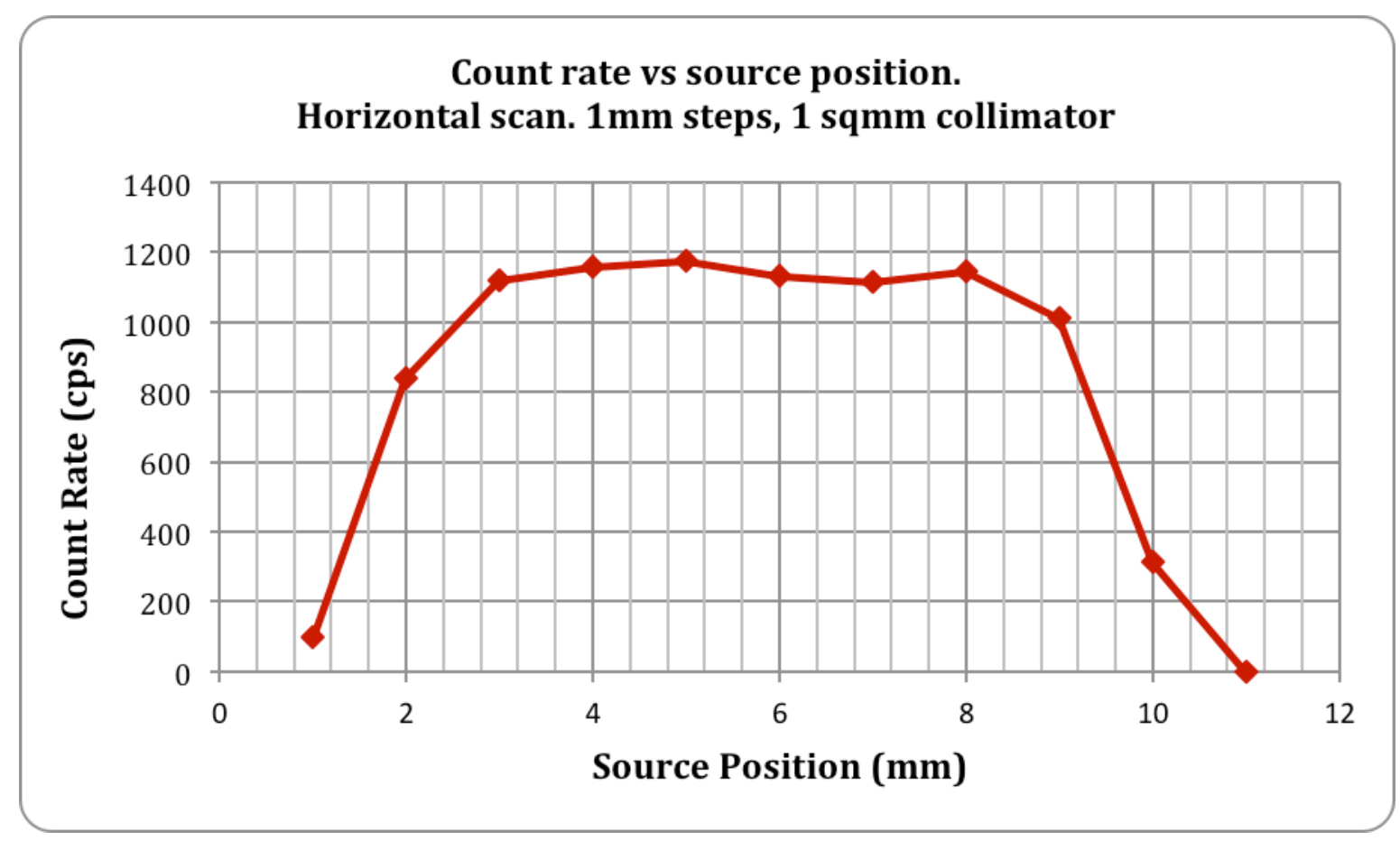

Figure 13: Collection Efficiency in horizontal scan, (Channel \#2, middle detector). 


\subsubsection{Spectrum results: resolution and peak to background}

Figures 14 and 15 are the Mn resolution results for each of the source positions in the vertical and horizontal driections, respectively. Similarly, figures 16 and 17 show the peak-tobackground ratio from the Mn spectra as the source is scanned. (Peak-to-background is defined as the ratio of the counts in the peak channel at $5.9 \mathrm{keV}$ to the average count per channel in the background between $900-1100 \mathrm{eV}$ ). No significant variation in energy resolution or peak-tobackground was found even at the edges of the SDD elements.

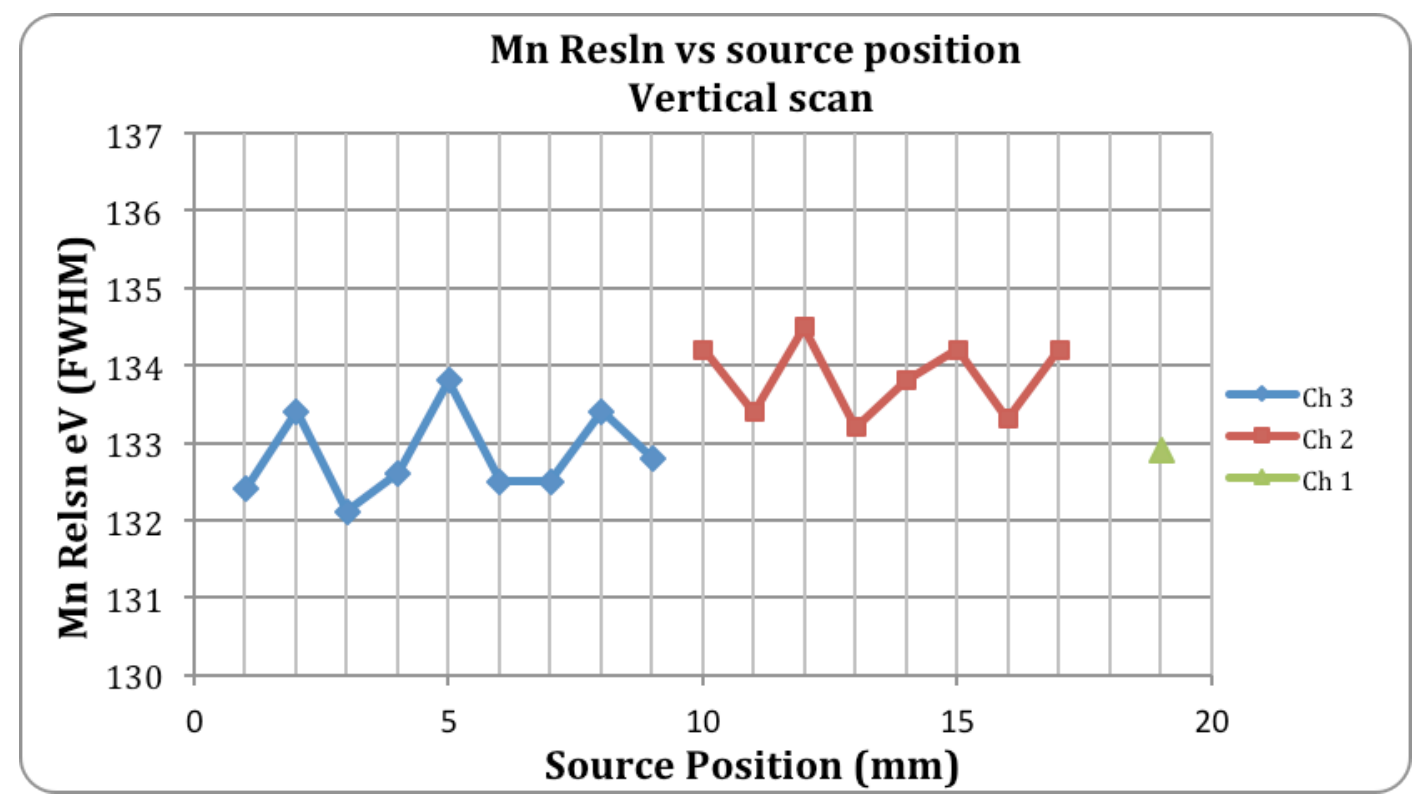

Figure 14. Mn resolution across horizontal scan

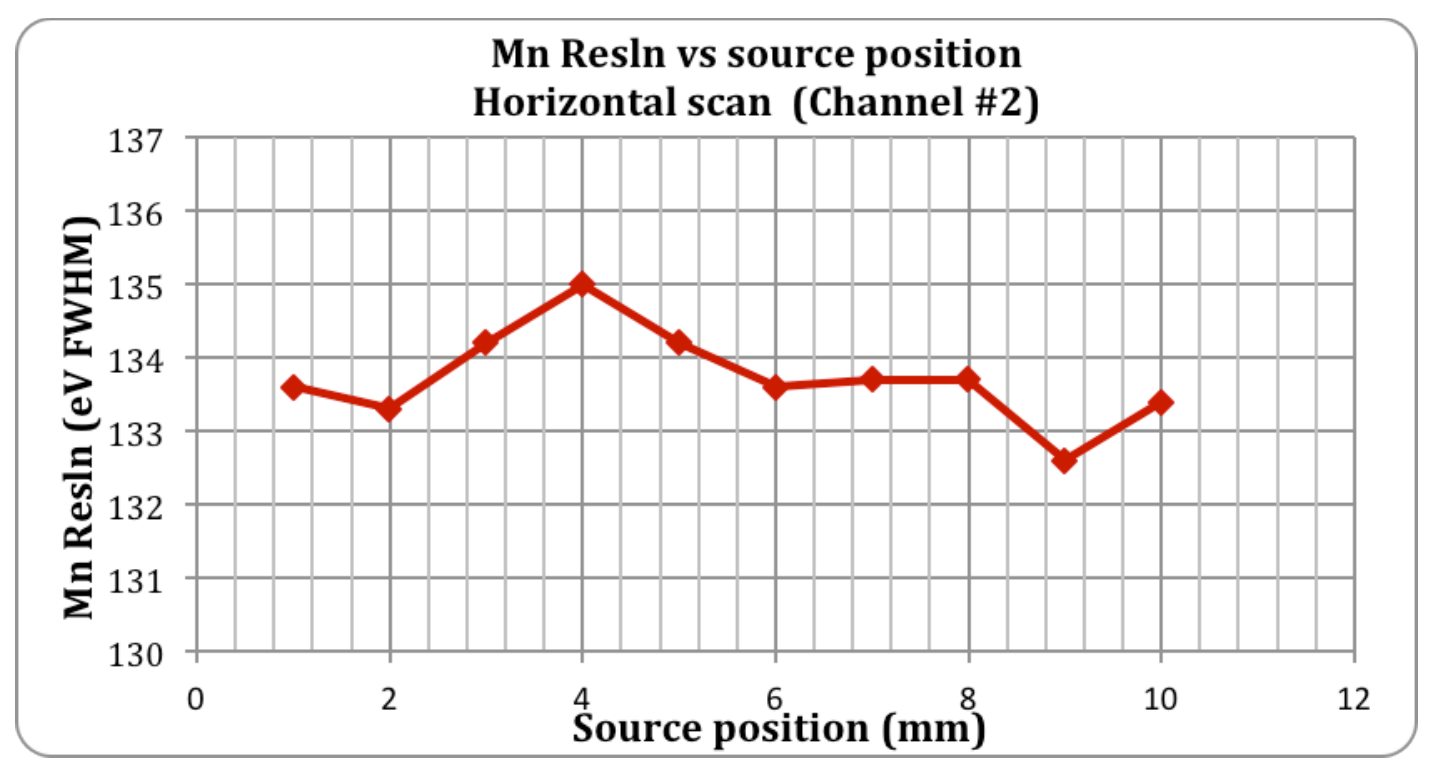


Figure 15. Mn resolution across vertical scan

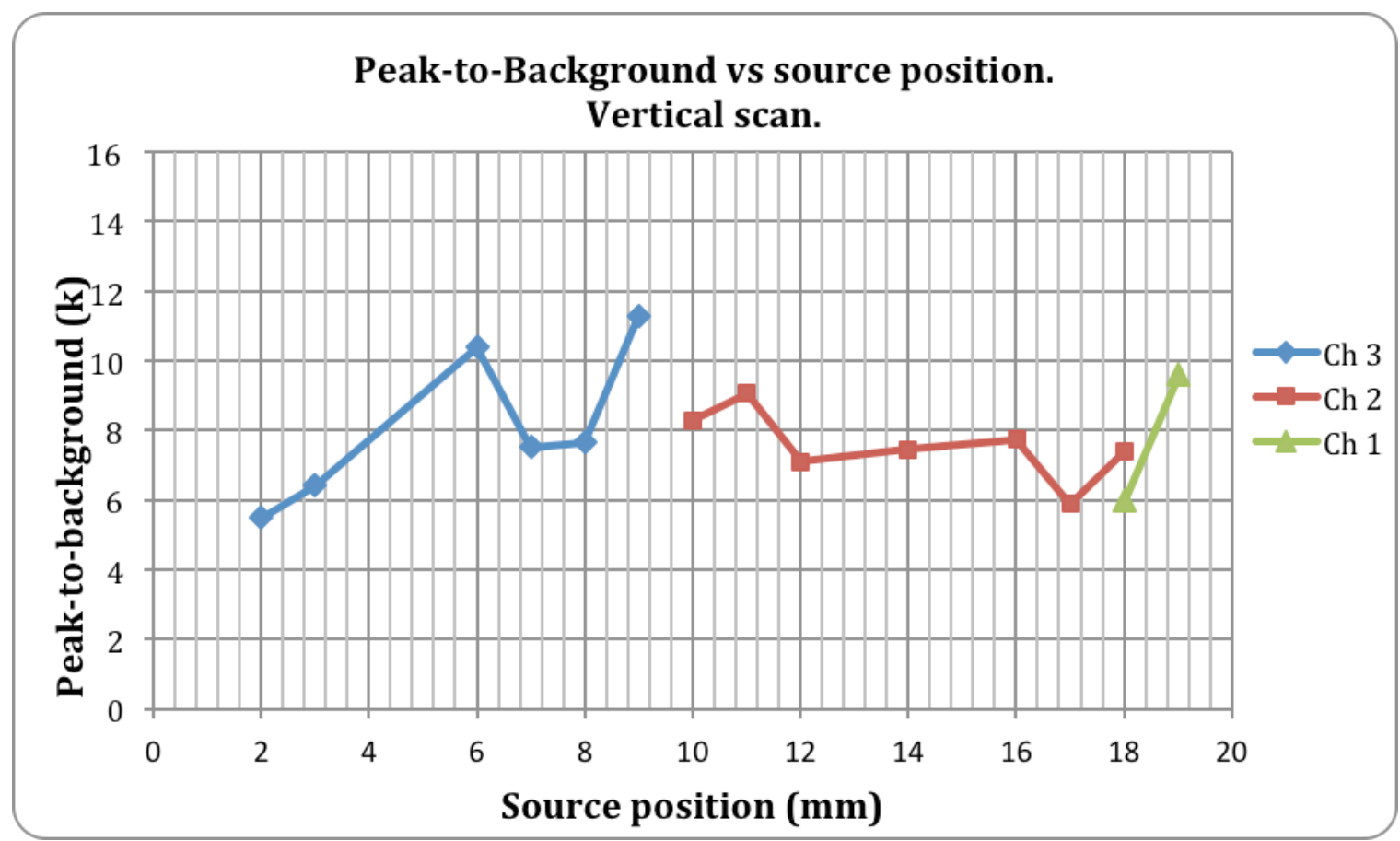

Figure $16.5 .9 \mathrm{~K}$ to $1 \mathrm{~K}$ Peak-to-Background across vertical scan. (X-ray tube source)

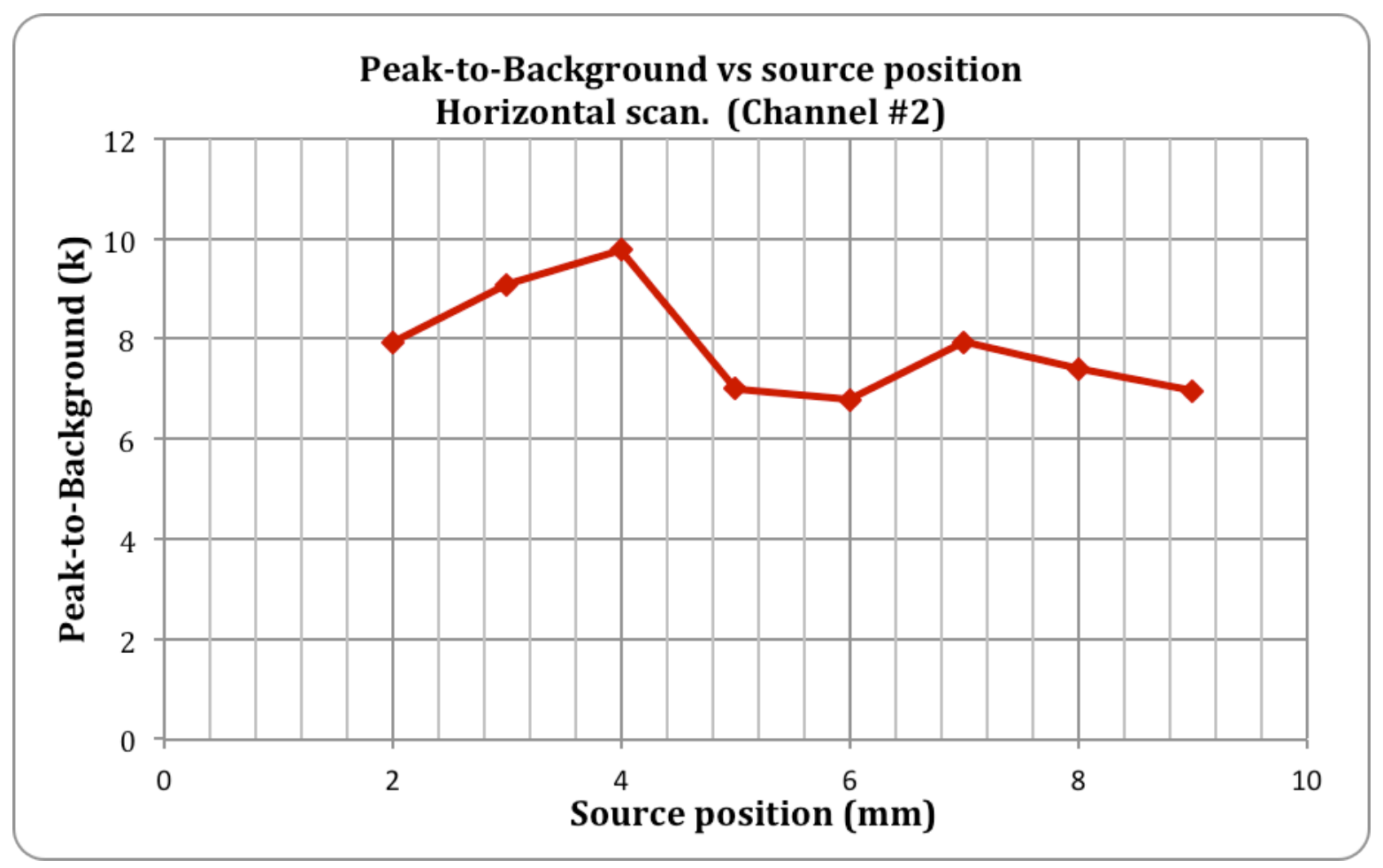

Figure $17.5 .9 \mathrm{~K}$ to $1 \mathrm{~K}$ Peak-to-Background across horizontal scan. (X-ray tube source) 


\subsubsection{Preamp signal risetime measurements}

Figures 18, 19 and 20 show the 10\%-90\% signal rise time as a function of source position, as measured from the raw preamp traces. 5 to 7 traces were collected for each scan position, and the mean rise-time calculated. The standard deviation on the mean values is shown by the error bars.

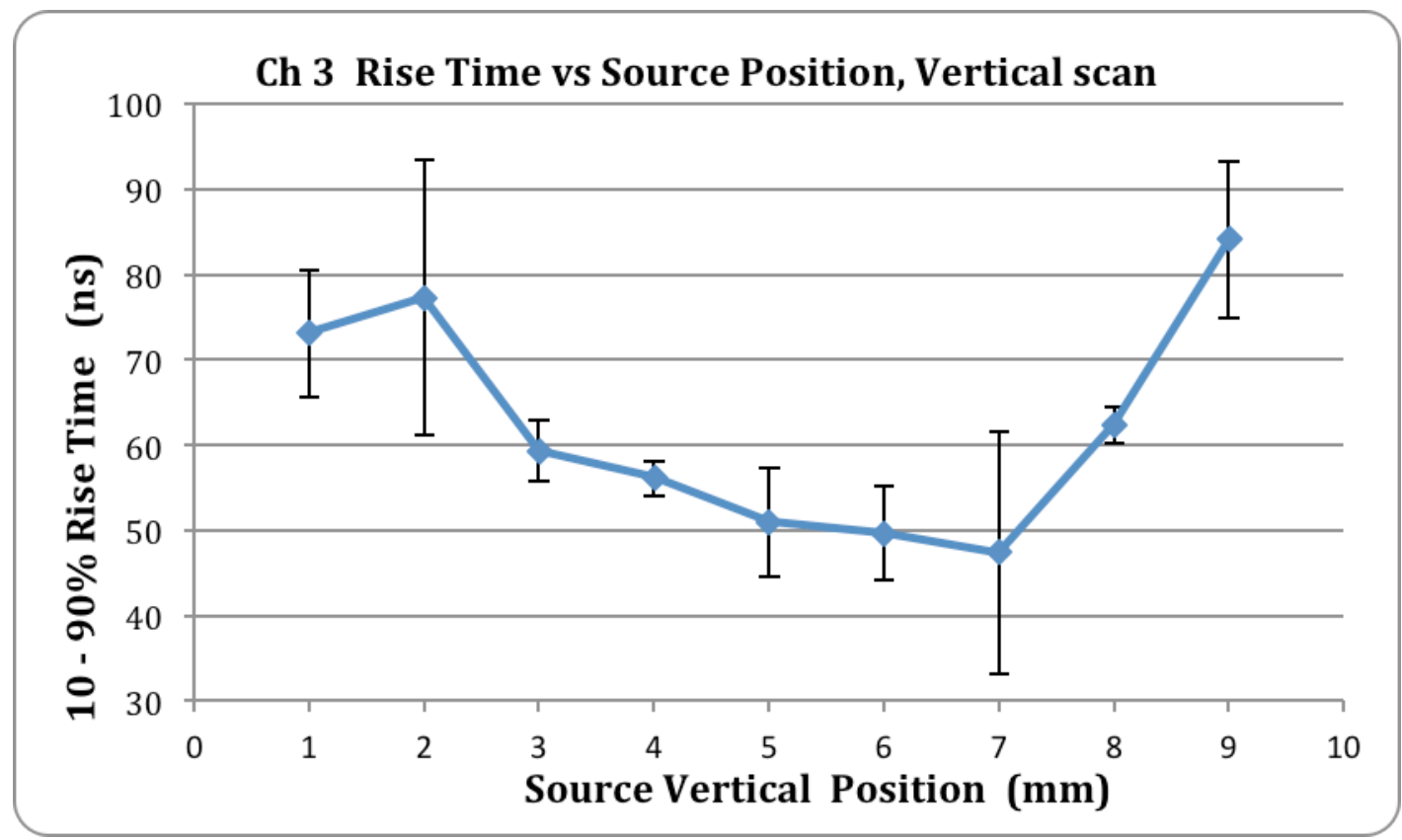

Figure 18: Rise Time vs vertical scan, channel \#3, (lower detector). 


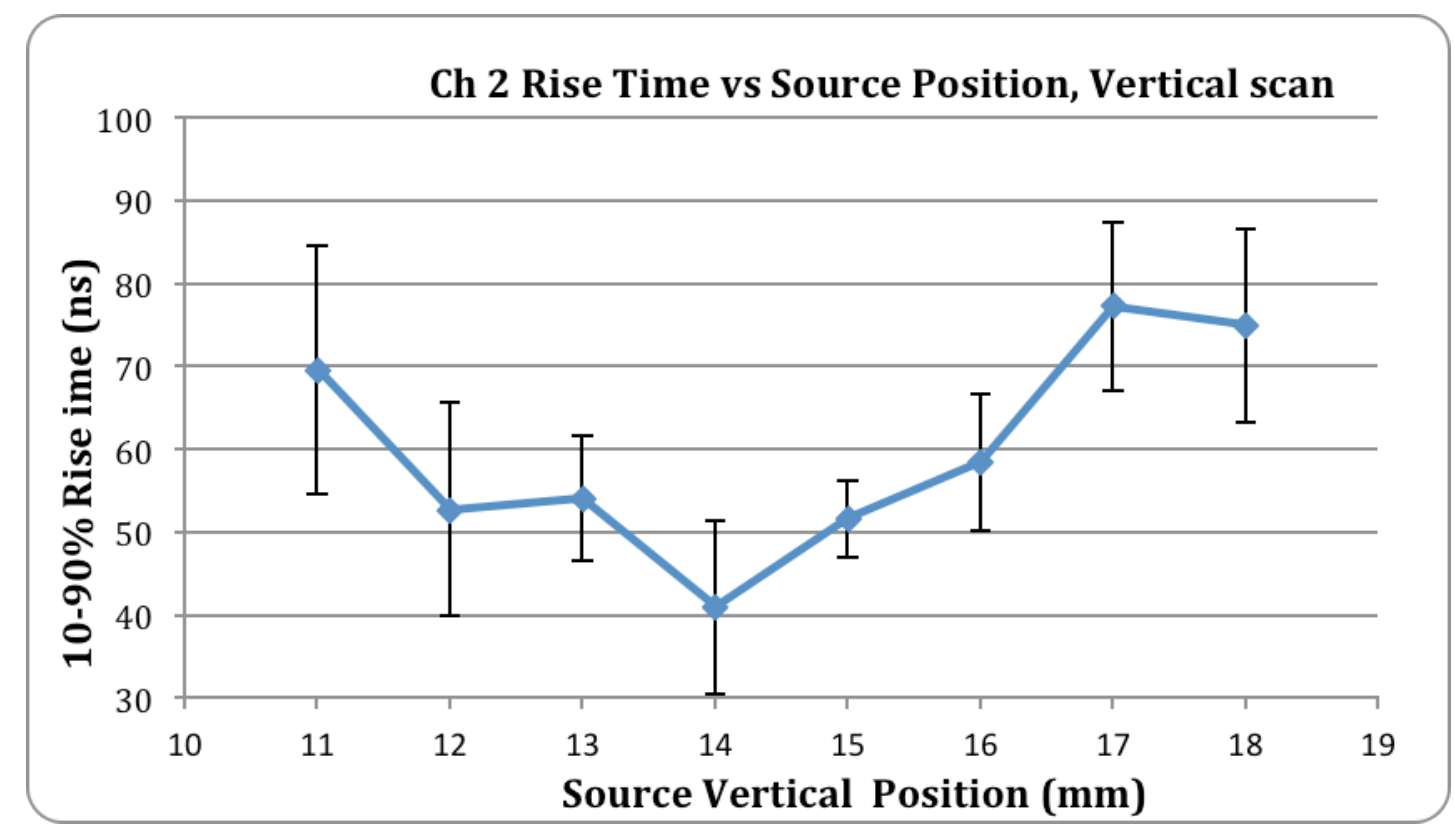

Figure 19: Rise Time vs vertical scan, channel \#2, (middle detector).

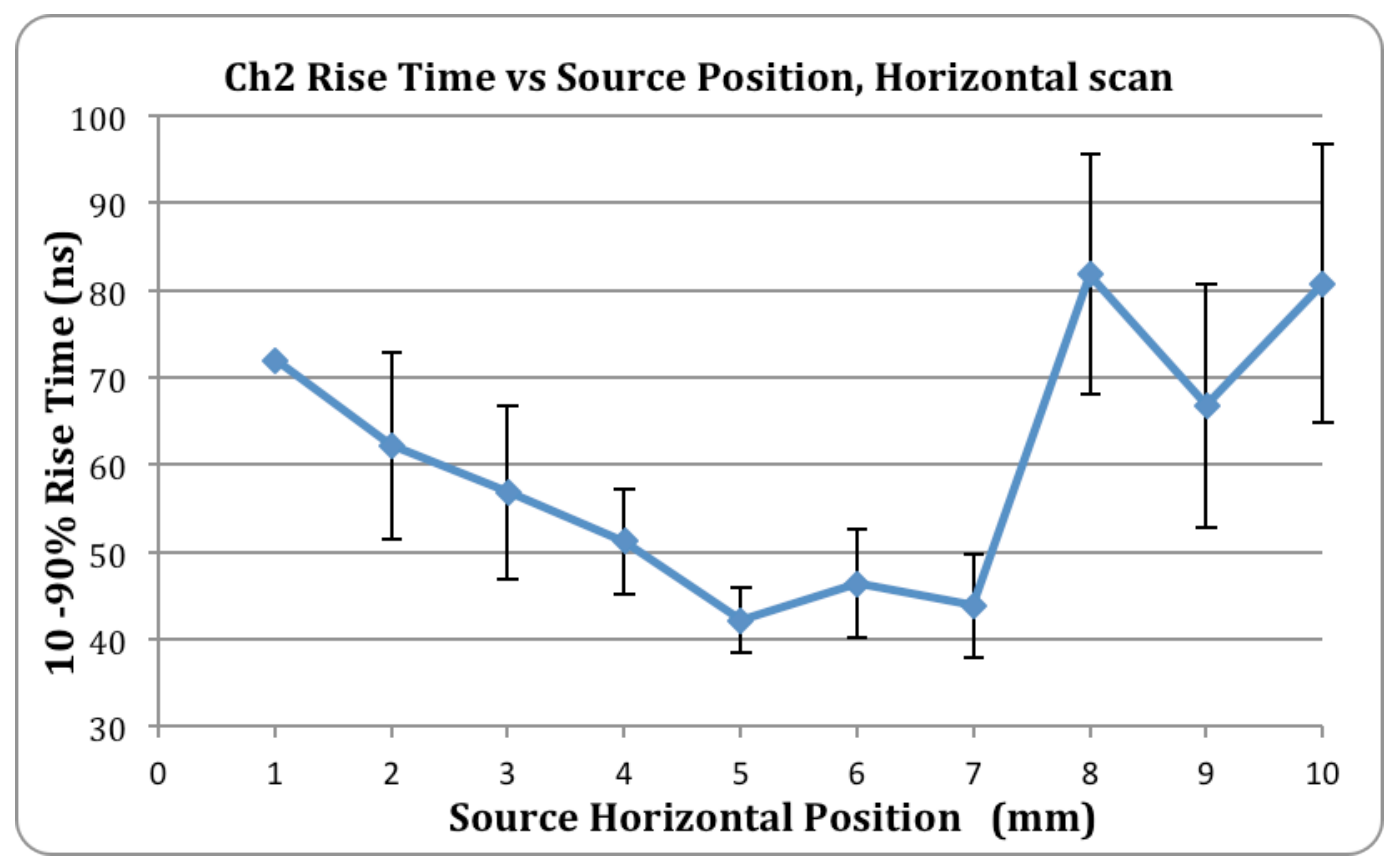

Figure 20: Rise Time vs Horizontal scan, channel \#2, (middle detector).

As expected, there was a trend towards faster rise times at the center of the detector. This is due to the intrinsic nature of the SDD, where longer drift distances from events at the edge result in more dispersion of electrons as they travel towards collection at the anode.

In addition to the scanned collimated measurements, an Fe-55 source was used to flood the detector without external collimation. A random sample of 50 traces was analyzed to create the rise time distribution in one detector element, as shown in figure 21. 


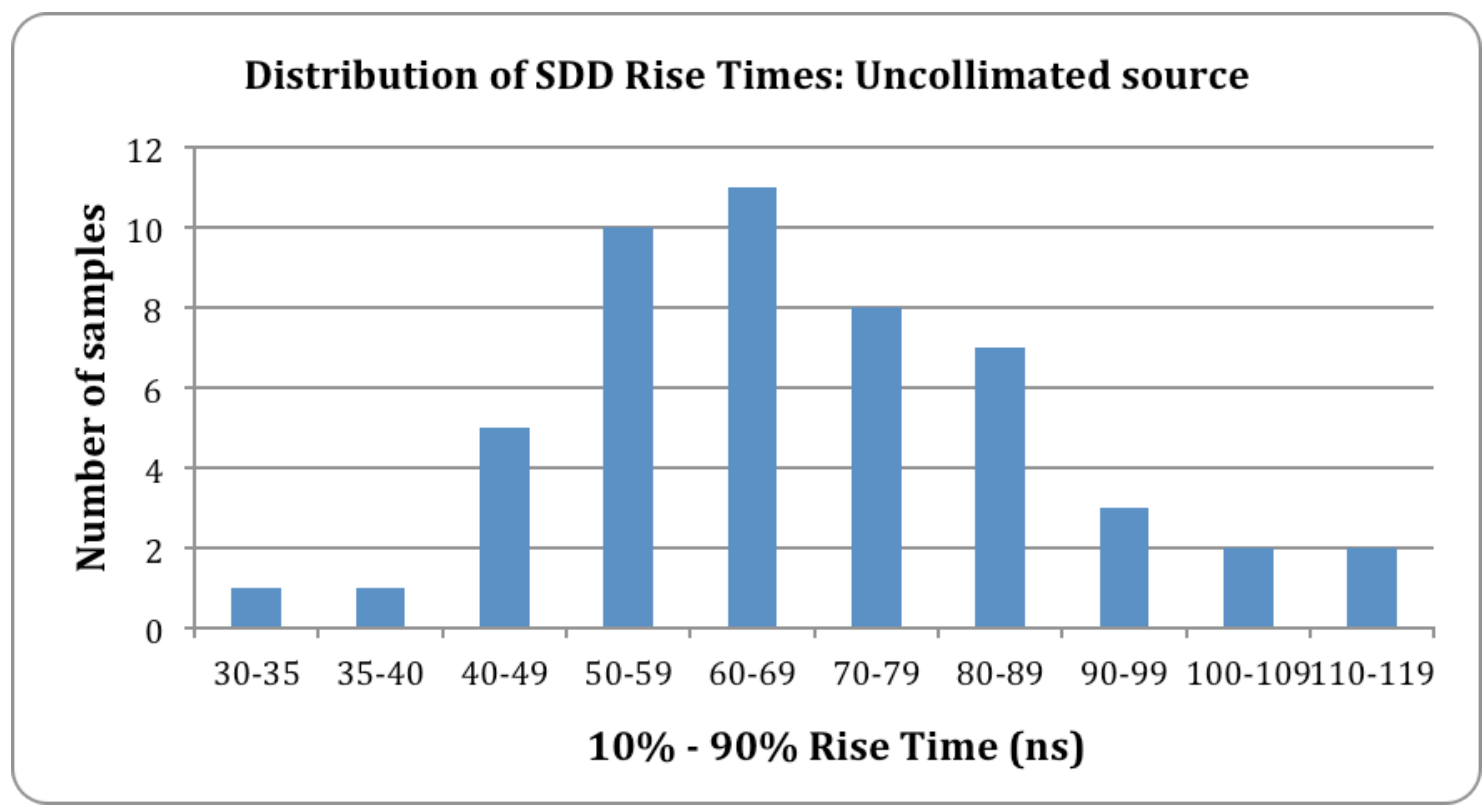

Figure 21 . Histogram of $10 \%-90 \%$ rise time in one detector element; uncollimated Fe-55 source.

It can be seen from figure 21 that $80 \%$ of pulses lay in the range $40-90 \mathrm{~ns}$, which is relatively fast for this type of detector. But for any given collimator position the range of rise times was quite large, as shown by the error bars in figures 18 through 20. For a sample size of six, there was quite often an outlier a factor of two higher or lower than the mean. There was also an infrequent ocurrance of very fast $(<40 \mathrm{~ns})$ but full-energy rise time signals. An example is shown in figure 22 below. Presumably these were events that were perfectly situated for optimum charge collection time; the lower observed limit of rise time may also be limited by the intrinsic performance of the Fet and preamp.

Within the data collected there appeared to be distinct classes of rise time signal, as illustrated in figures 23 to 26. Most events were some combination of the extreme examples shown. There does not appear to be a clear cut relationship between the "class" of signal and its surface location, besides the obvious trend of faster pulses in the middle. The depth of the X-ray interaction may also have played a part. 


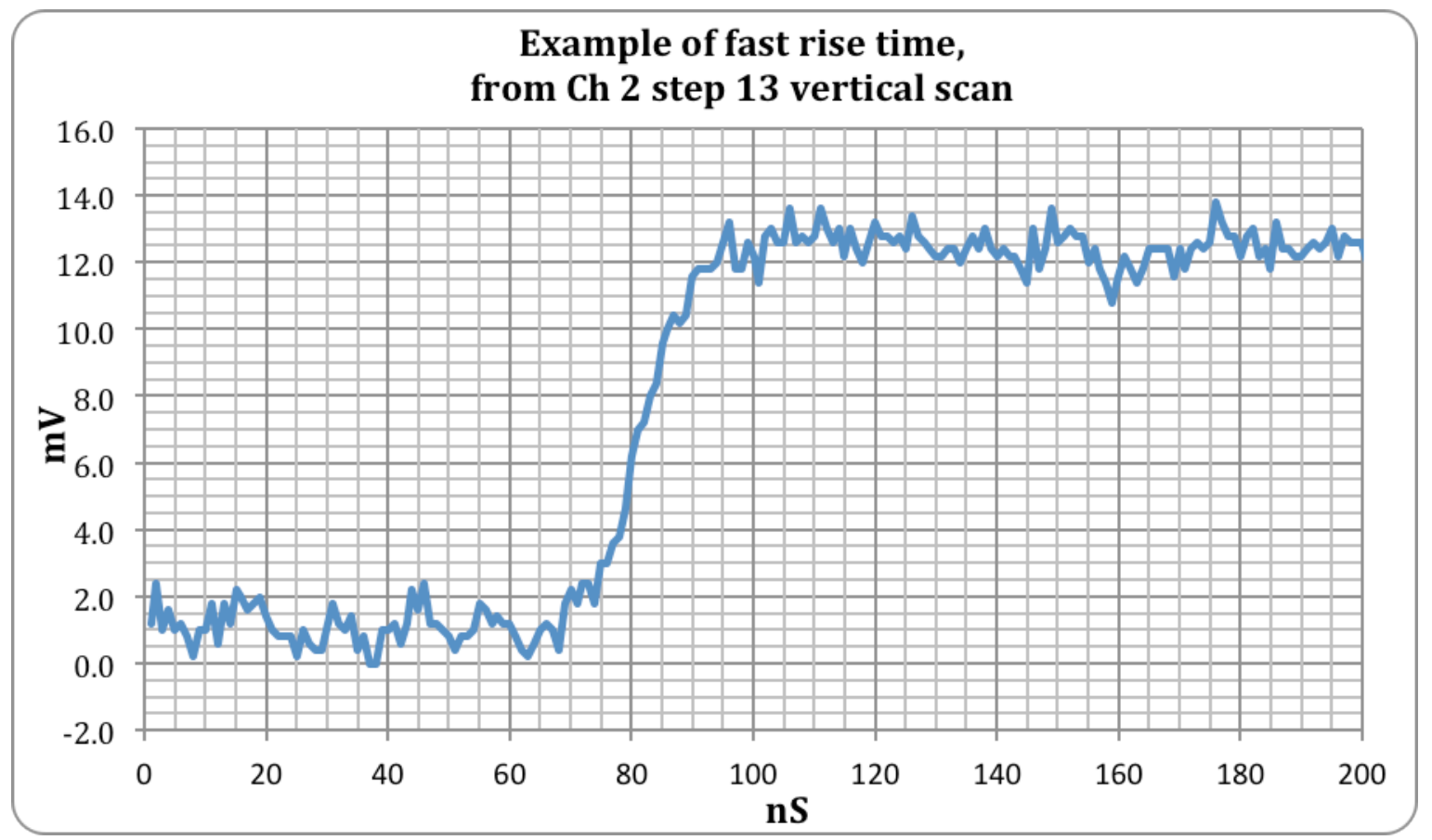

Figure 22. Example of fast rise time. (From middle of detector element). $10 \%-90 \%=30 \mathrm{~ns}$

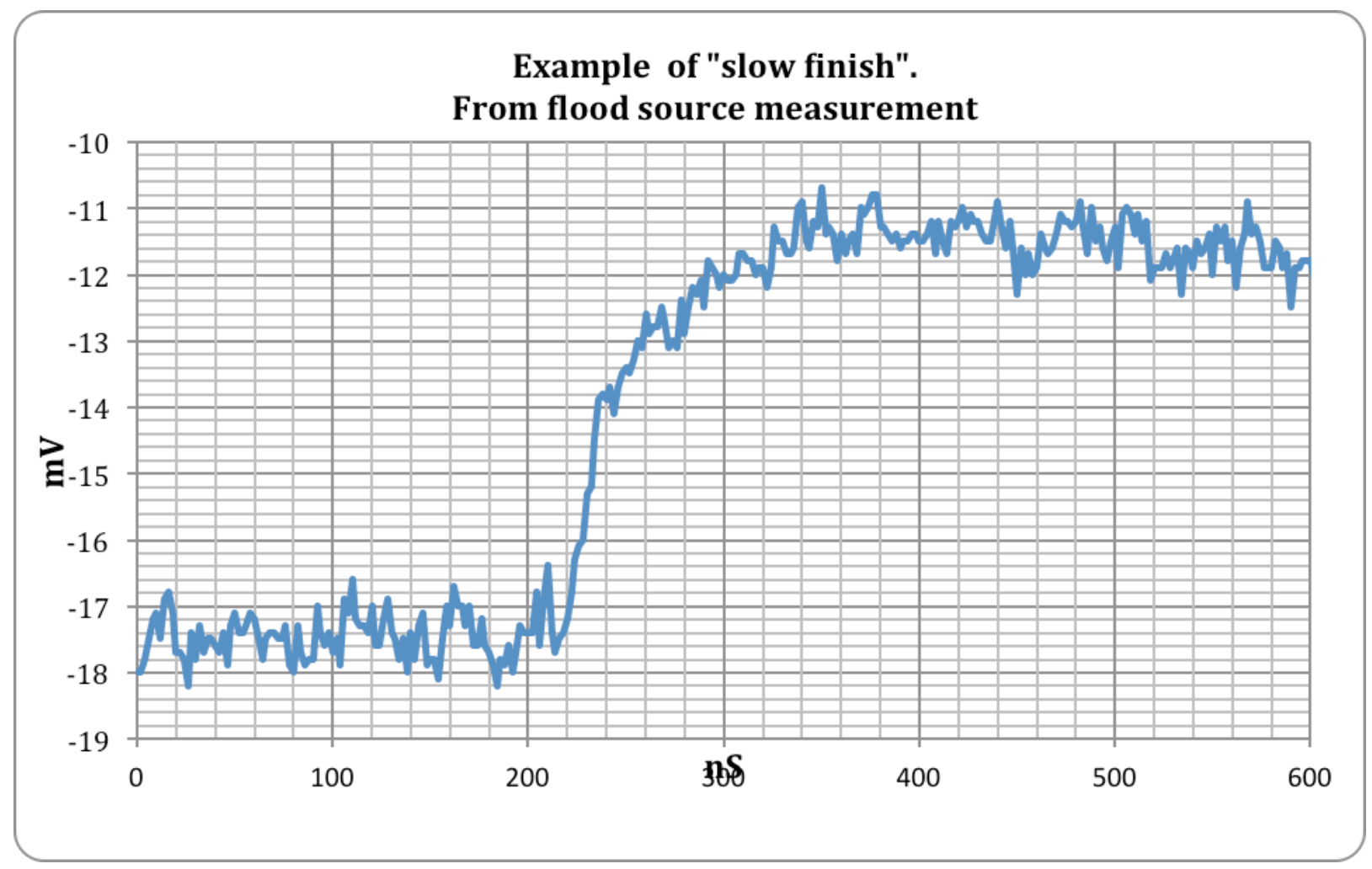

Figure 23: Example of fast rising edge, but slow finish: $10 \%-90 \%=80 \mathrm{~ns}$. 


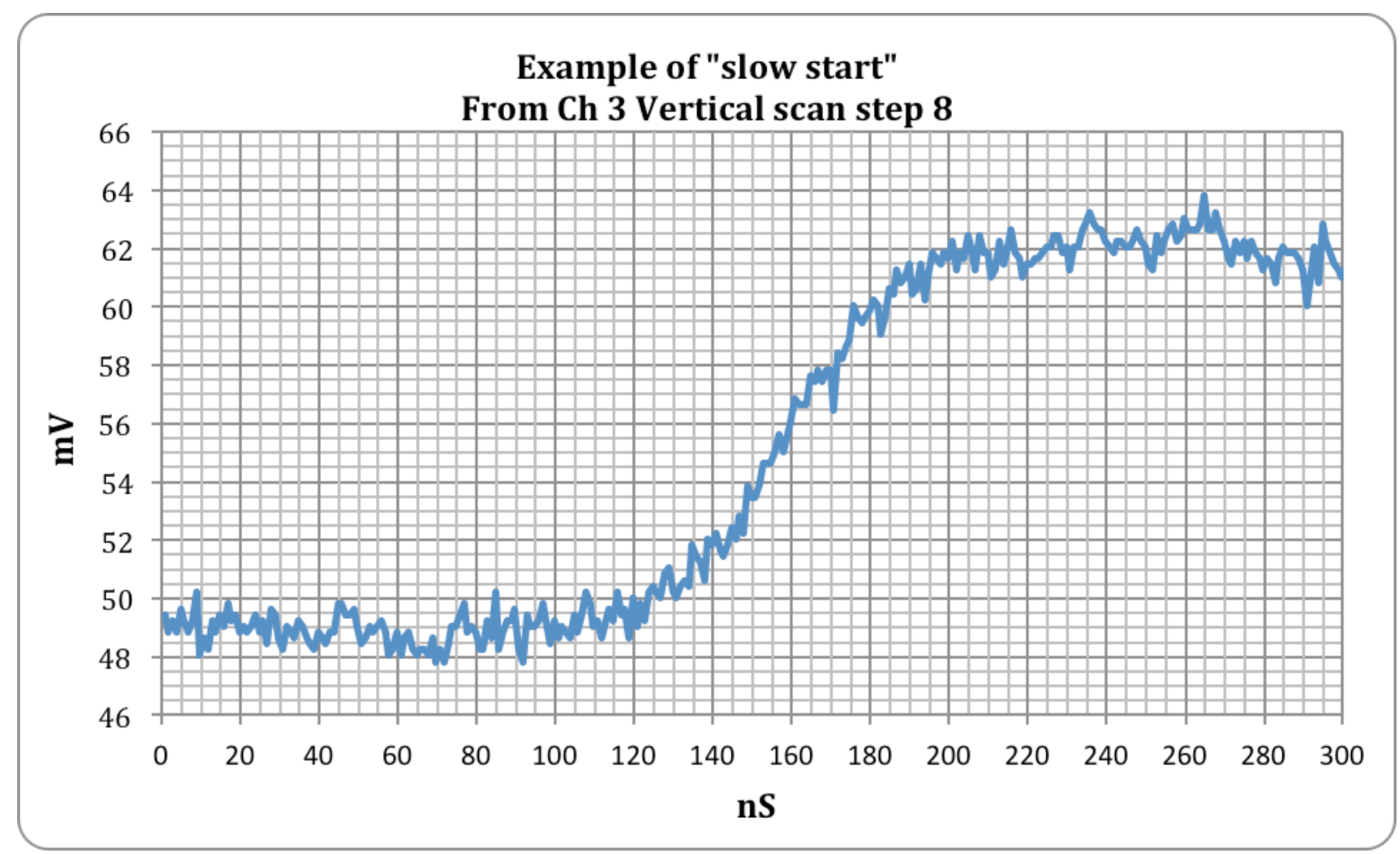

Figure 24. Example of slow rising edge. $10 \%-90 \%=60 \mathrm{~ns}$

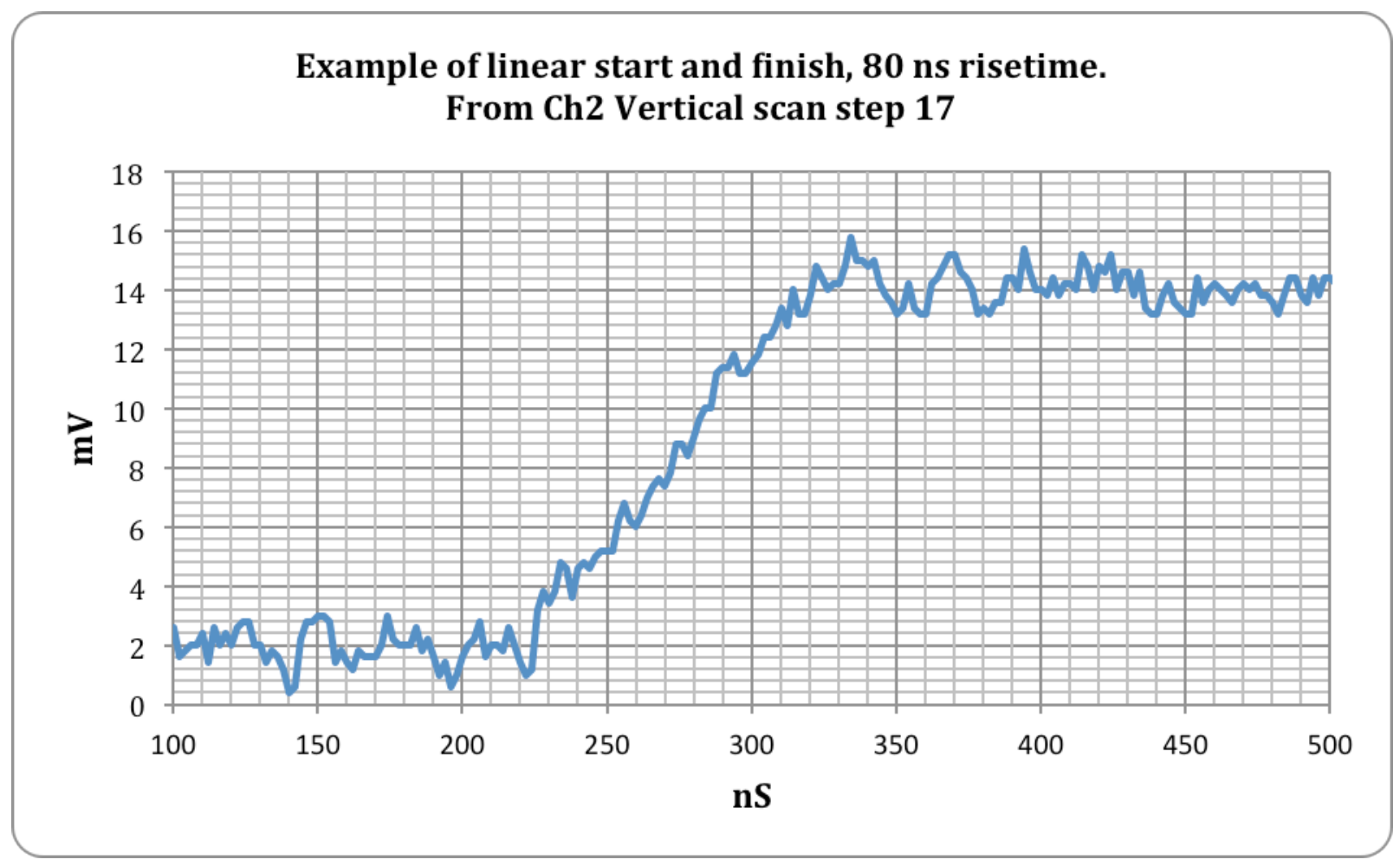

Figure 25. Example of "linear" rise: 80ns. Such events are not confined to short rise times. 


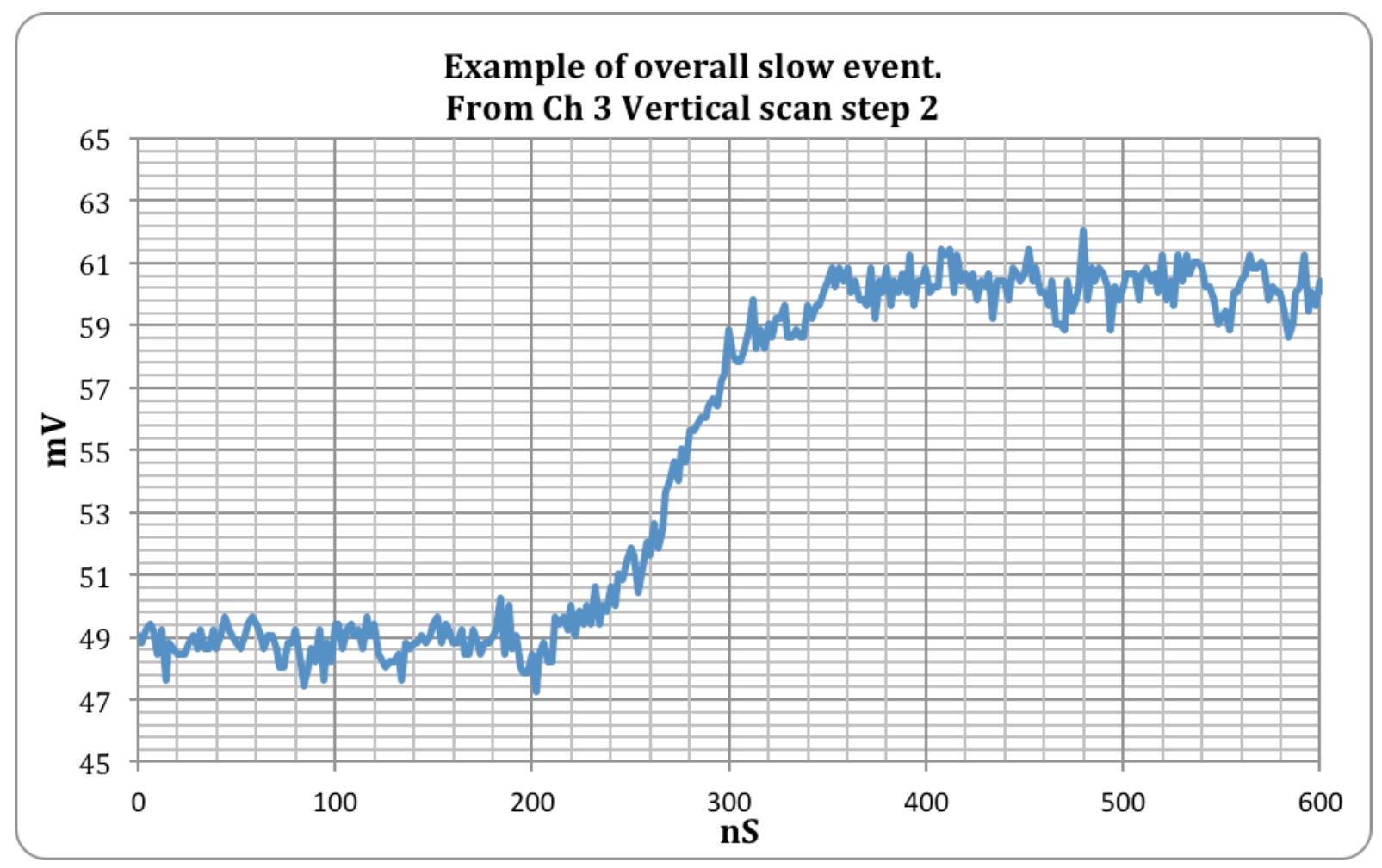

Figure 26. Example of overall slow rise time: $10 \%-90 \%=100 \mathrm{~ns}$

\subsection{Energy Resolution and count rate performance}

The performance of each of the 100-sqmm SDD elements was evaluated with respect to energy resolution vs peaking time, energy resolution vs count rate, and cross-talk from other detector elements.

The encapsulated SDD package consisted of two $30 \mathrm{~mm}$ x $10 \mathrm{~mm}$ detector segments each made from a monolithic strip of three 100-sqmm SDD elements. The two elements had been designated by the manufacturer as detector \#2 and detector \#4, and this convention is maintained in the report. Each segment was coupled to a 3-channel preamplifier that applied one reset signal simultaneously to all three channels, with an option for an internally generated or external reset drive. The TTL reset signal from detector \#4 was wired to external reset drive of detector \#2 causing all six channels to reset simultaneously, thereby reducing cross-talk between the channels.

The two internal Peltier coolers (one for each detector segment) were powered in series with 12V/1.9A. The chiller temperature was controlled at $20^{\circ} \mathrm{C}$. The detector temperature was stable at about $-39{ }^{\circ} \mathrm{C}$, (both segments), and the reset period with no irradiation was about $20 \mathrm{~ms}$. Two 4-channel xMap digital signal processors were used to generate spectra and count rate information. 
Final technical report: High Rate X-ray Fluorescence Detector

\subsubsection{Low count rate performance}

Table 1 and figure 27 show the observed Mn resolution for various signal processor peaking times, using an Fe-55 source at 1 kcps.

\begin{tabular}{|c|c|c|c|c|c|c|c|c|c|c|c|c|c|}
\hline & & \multicolumn{12}{|c|}{ Peaking Time $(\mu \mathrm{S})$} \\
\hline & $\mathrm{Ch}$ & 0.1 & 0.2 & 0.3 & 0.5 & 0.72 & 1 & 1.5 & 2 & 3.04 & 4 & 6 & 8 \\
\hline \multirow[t]{3}{*}{ Det2 } & 1 & 203.8 & 176.2 & 164.3 & 150.0 & 144.1 & 137.9 & 134.4 & 132.8 & 132.5 & 132 & 134 & 133.8 \\
\hline & 2 & 207.2 & 178.9 & 163.7 & 149.5 & 143.9 & 139 & 135.3 & 133.6 & 134.3 & 132.4 & 135.1 & 136.7 \\
\hline & 3 & 203.6 & 177.1 & 163.3 & 149.4 & 142.3 & 139.6 & 135.9 & 134.2 & 133.5 & 133.5 & 133.6 & 135.4 \\
\hline \multirow[t]{3}{*}{ Det4 } & 1 & 202.2 & 178.2 & 163.6 & 150.9 & 143.1 & 139.9 & 135.7 & 133.5 & 133.7 & 132.6 & 135.4 & 135.6 \\
\hline & 2 & 202.3 & 173.3 & 162.3 & 149.9 & 142.8 & 138.6 & 136.7 & 135.8 & 134.9 & 135.4 & 135.7 & 141 \\
\hline & 3 & 204.3 & 177.4 & 163.6 & 151.1 & 143.6 & 138.5 & 135.6 & 134.3 & 133.2 & 133.1 & 134.1 & 136.7 \\
\hline
\end{tabular}

Tabel 1. Mn resolution (eV FWHM) versus peaking time ( $\mu \mathrm{s})$ for all 6 SDD elements.

Figure 28 is the corresponding Fe-55 spectrum from detector \#2, channel 1at $4 \mu$ s peaking time. The $5.9 \mathrm{keV}$ to $1 \mathrm{keV}$ peak-to-background measured $5 \mathrm{k}: 1$.

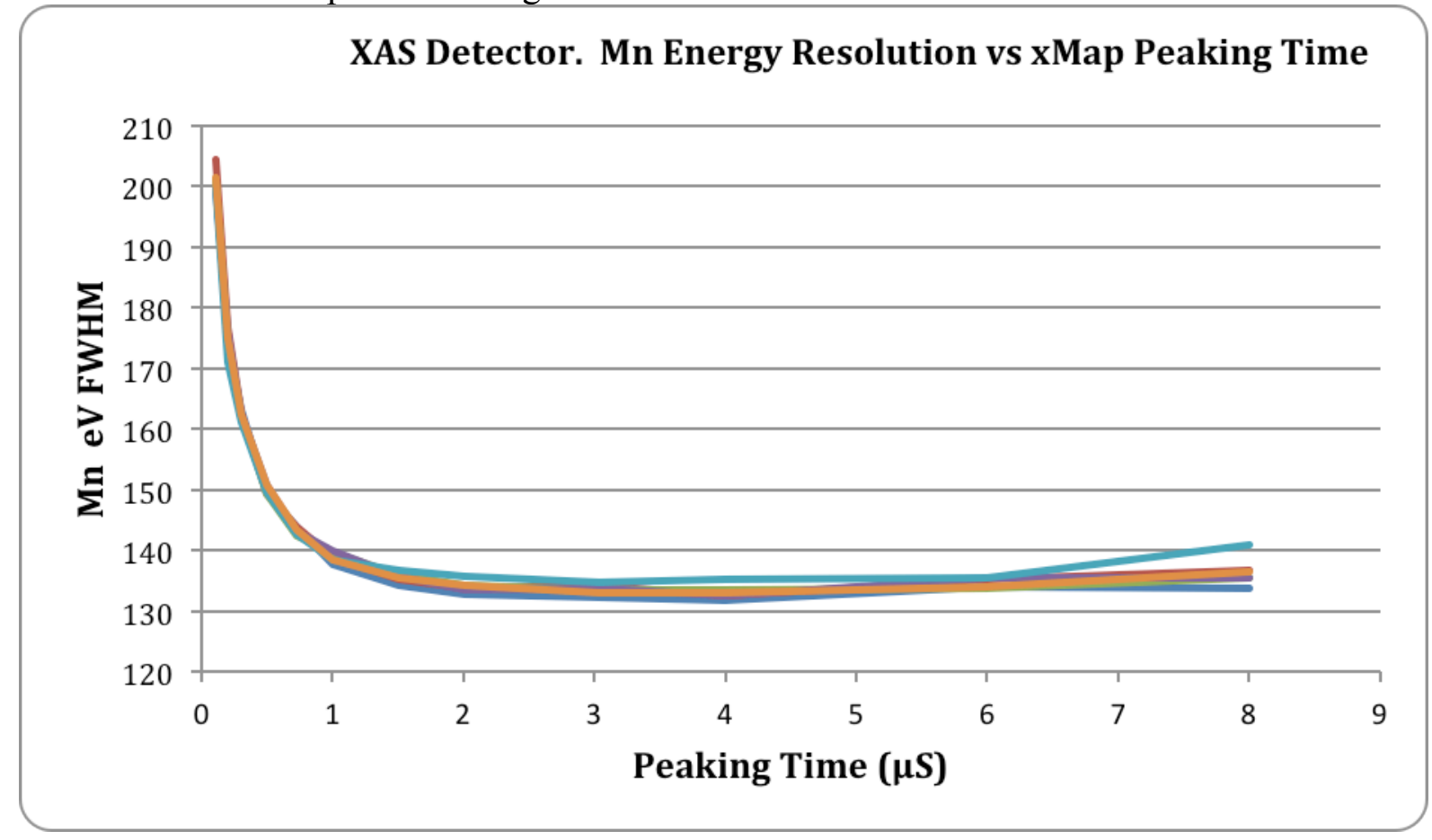

Figure 27. Plotted data from Table 1, for all channels 


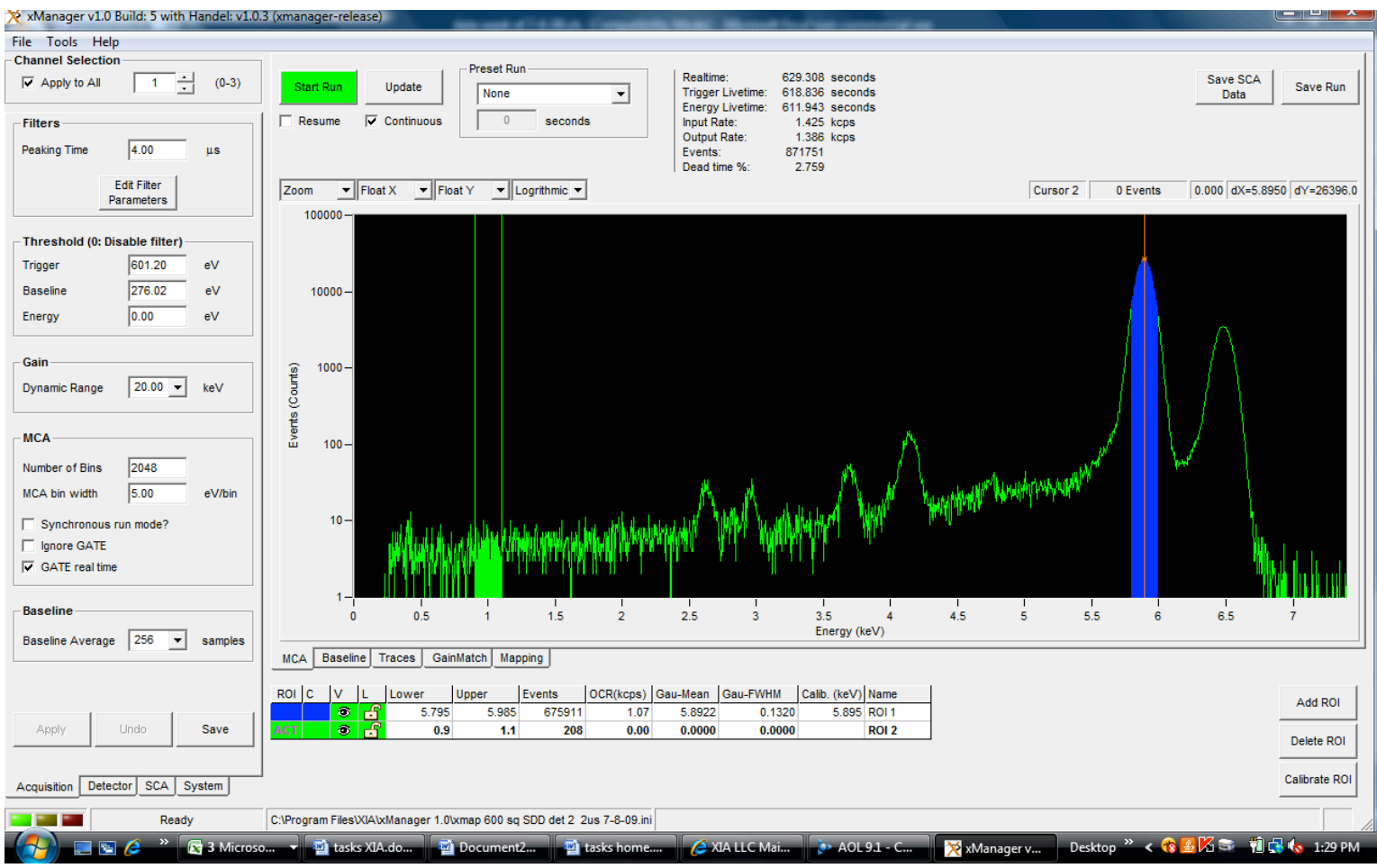

Figure 28. Mn Spectrum at $4 \mu$ s peaking time. $5.9 \mathrm{KeV}: 1 \mathrm{keV}$ Peak-to-Background = 5.1K. (Det 2, Ch 1$)$

\subsubsection{Energy resolution vs count rate}

The Fe-55 source was replaced with an x-ray tube and Mn sample to conduct high rate measurements. Table 2 indicates the resolution with $0.1 \mu$ s peaking $(0.3 \mu$ sap) at various input count rates up to 1 Mcps. The data in the table is plotted in figures 29 , and a representative spectrum at 1 Mcps is shown in figure 30. Figure 31 displays the output count rate versus input count rate for the conditions of Table 2 .

\begin{tabular}{|l|c|c|c|c|c|c|c|c|c|}
\hline \multicolumn{2}{|l|}{$\mathbf{0 . 1} \boldsymbol{\mu s}$ Peaking } & \multicolumn{10}{|c|}{ ICR (kcps) } \\
\hline & Ch & $\mathbf{7}$ & $\mathbf{5 0}$ & $\mathbf{1 0 0}$ & $\mathbf{3 0 0}$ & $\mathbf{5 0 0}$ & $\mathbf{7 0 0}$ & $\mathbf{8 0 0}$ & $\mathbf{1 0 0 0}$ \\
\hline Det 2 & 1 & 218.3 & 218 & 221 & 230.9 & 239.3 & 245.8 & 249.6 & 256.2 \\
\hline & 2 & 218 & 220.5 & 220.8 & 228.8 & 234.4 & 238.8 & 241.7 & 246.5 \\
\hline & 3 & 220.7 & 220.8 & 220 & 225.2 & 228.4 & 229.9 & 230.9 & 232.3 \\
\hline Det 4 & 1 & 216.3 & 220.2 & 220.7 & 231 & 239.5 & 246.6 & 250.1 & 256.5 \\
\hline & 2 & 214.7 & 214.9 & 216.8 & 221.1 & 225 & 228.6 & 229.9 & 233.1 \\
\hline & 3 & 223.2 & 221.7 & 223.9 & 231.9 & 236.6 & 240.6 & 242.2 & 248.7 \\
\hline
\end{tabular}

Table 2. Mn Resolution (eV FWHM) vs Input Count Rate (kcps) at $0.1 \mu \mathrm{S}$ Peaking (0.3 $\mu \mathrm{S}$ gap) 


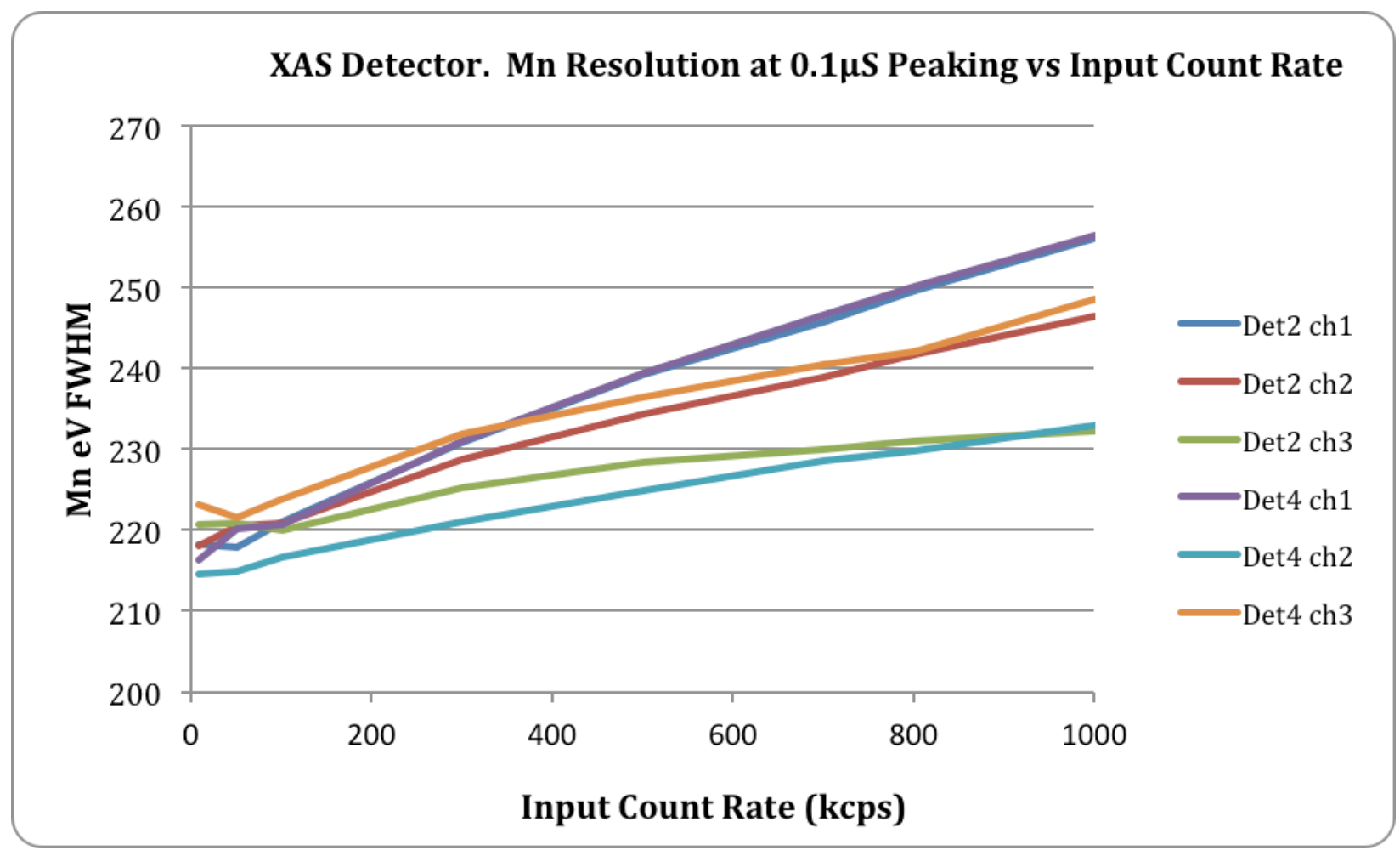

Figure 29. Mn energy resolution vs Input Cout Rate, from Table 2. (0.1 $\mu$ s Peaking)

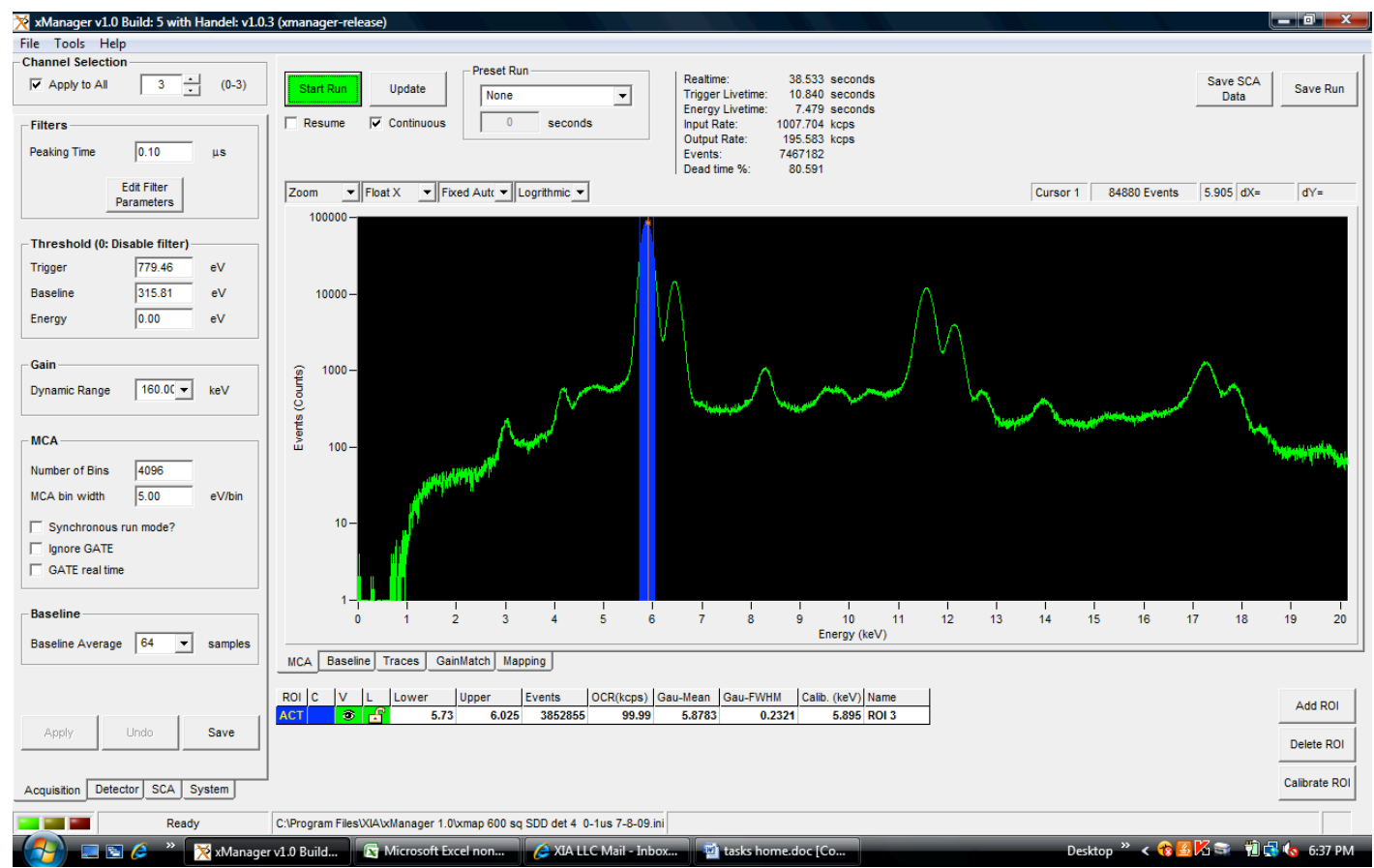


Figure 30. Spectrum collected at 1 Mcps using an x-ray tube and Mn sample. Peaking time $=0.1 \mu \mathrm{s}$

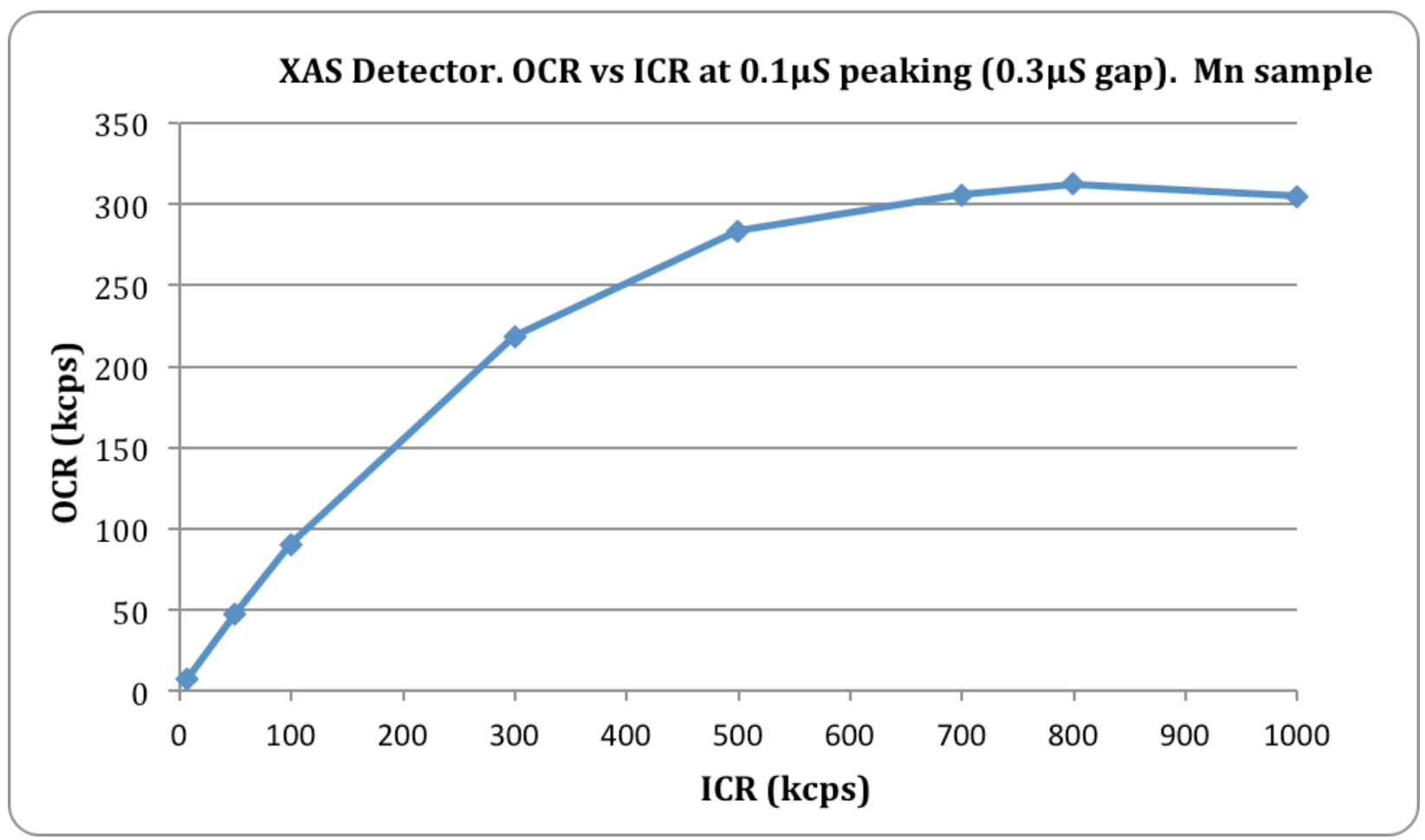

Figure 31. Output Count Rate vs Input Count Rate for $0.1 \mu$ s peaking $(0.3 \mu$ s gap):

Same conditions as Table 2

Table 3 and figures 32 and 33 show the results of high rate measurements with the x-ray tube and Mn sample, but this time with the peaking time extended to $0.3 \mu \mathrm{s}$, (and $0.3 \mu \mathrm{s}$ gap), resulting in improved energy resolution but lower maximum throughput.

\begin{tabular}{|l|c|c|c|c|c|c|c|c|c|}
\hline \multicolumn{1}{|c|}{$\mathbf{0 . 3 \mu s}$ Peaking } & \multicolumn{10}{|c|}{ ICR ((kcps) } \\
\hline & Ch & $\mathbf{7}$ & $\mathbf{5 0}$ & $\mathbf{1 0 0}$ & $\mathbf{3 0 0}$ & $\mathbf{5 0 0}$ & $\mathbf{7 0 0}$ & $\mathbf{8 0 0}$ & $\mathbf{1 0 0 0}$ \\
\hline Det 2 & 1 & 168.7 & 170.8 & 172.5 & 178.8 & 182.4 & 187.3 & 190.9 & 194.5 \\
\hline & 2 & 168.5 & 170.5 & 171.2 & 176.4 & 178.7 & 183 & 182.7 & 185.3 \\
\hline & 3 & 167.8 & 169.5 & 169.6 & 171.4 & 174.9 & 175 & 174.3 & 175.3 \\
\hline Det 4 & 1 & 167.7 & 170.4 & 172.3 & 179 & 182.9 & 186 & 189.9 & 192.3 \\
\hline & 2 & 166.7 & 167.5 & 168.4 & 172.5 & 174.3 & 176.8 & 178.9 & 179.2 \\
\hline & 3 & 169.3 & 170.1 & 170.9 & 174.2 & 176.9 & 179.7 & 181.8 & 182.6 \\
\hline
\end{tabular}

Table 3. Mn Resolution (eV FWHM) vs Input Count Rate (kcps) at $0.3 \mu \mathrm{S}$ Peaking (0.3 $\mu \mathrm{S}$ gap) 


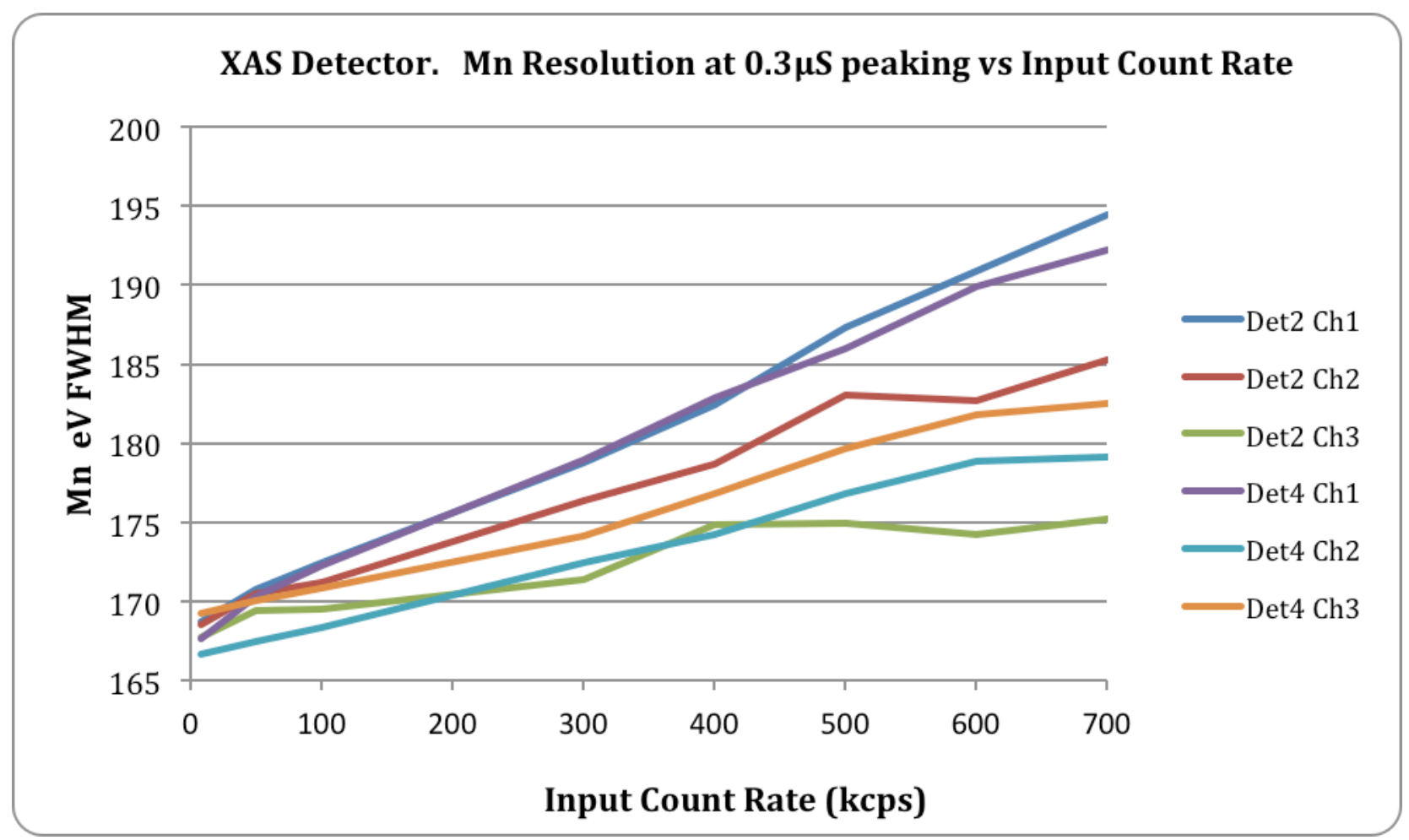

Figure 32. Mn energy resolution vs Input Cout Rate, from Table 3. (0.3 $\mu$ s Peaking) 


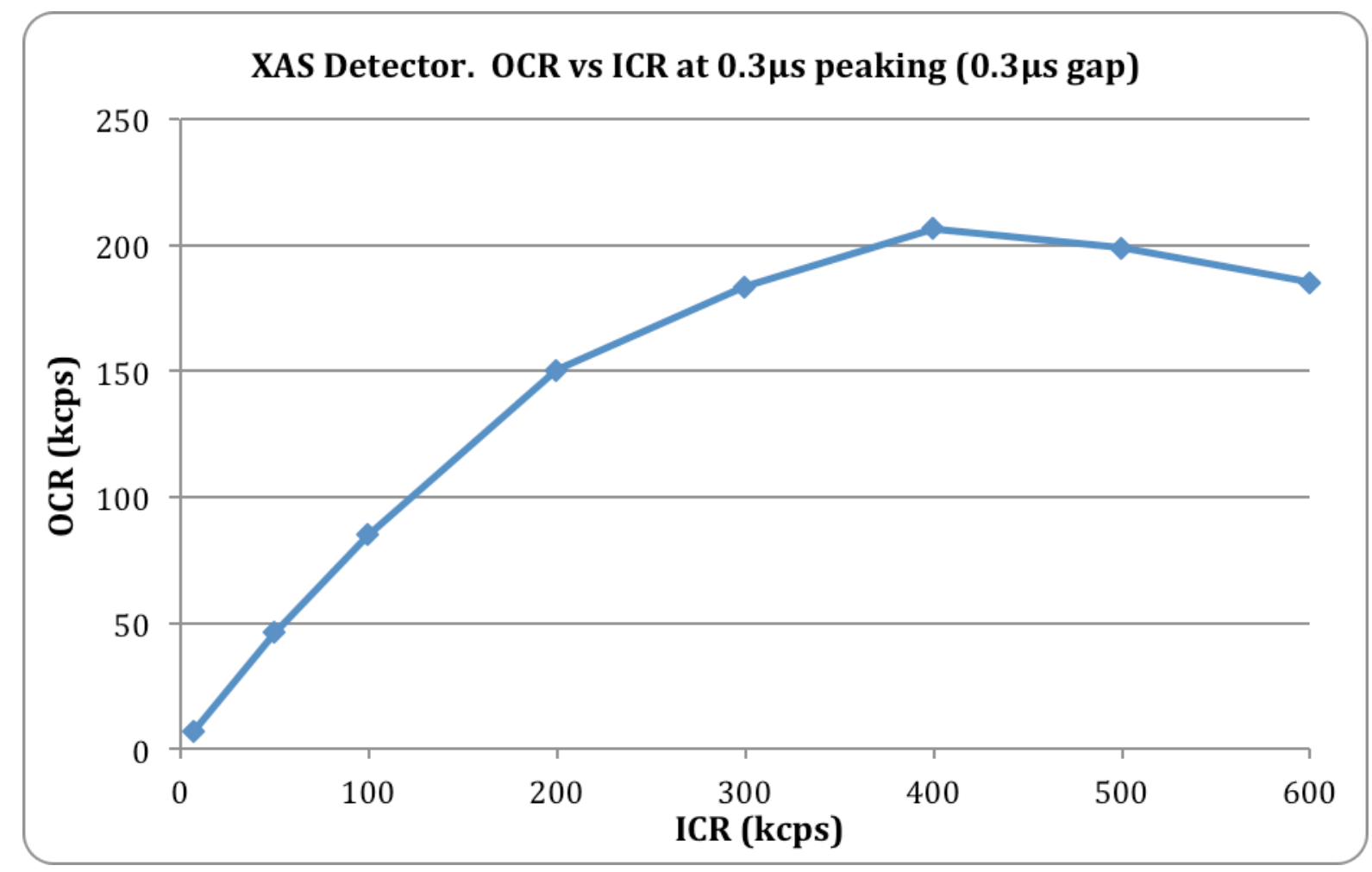

Figure 33. Output Count Rate vs Input Count Rate for $0.3 \mu$ s peaking ( $0.3 \mu$ sap):

Same conditions as Table 3

\subsection{Cross Talk Effects}

The individual reset signals to each channel were transmitted through the detector ribbon cable, resulting in coupling between the reset and Fet drain signal and the production of large positive and negative reset transients at the preamp output. With the two detector segments resetting independently there was significant cross-talk between the reset of one segment and the input signals of the other. The following measurements were performed with the resets from the two segments synchronized to reduce cross-talk, (which is the normal mode of operation), with a view to evaluating any residual cross-talk effects.

For purposes of the test, Detector \#2 (reset slave) was blanked off, and Detector \#4 (reset master) was irradiated with $4 \mathrm{kcps} F-55$. The processor peaking time was $0.1 \mu \mathrm{s}$. Figure 34 shows the resulting spectrum in Detector $\# 2$ channel 1 for a $1000 \mathrm{sec}$ count. The total counts in the spectrum amount to 462 including some Fe-55. All channels showed similar results, with the conclusion that detector \#2 saw no significant cross-talk from detector \#4. 
Final technical report: High Rate X-ray Fluorescence Detector

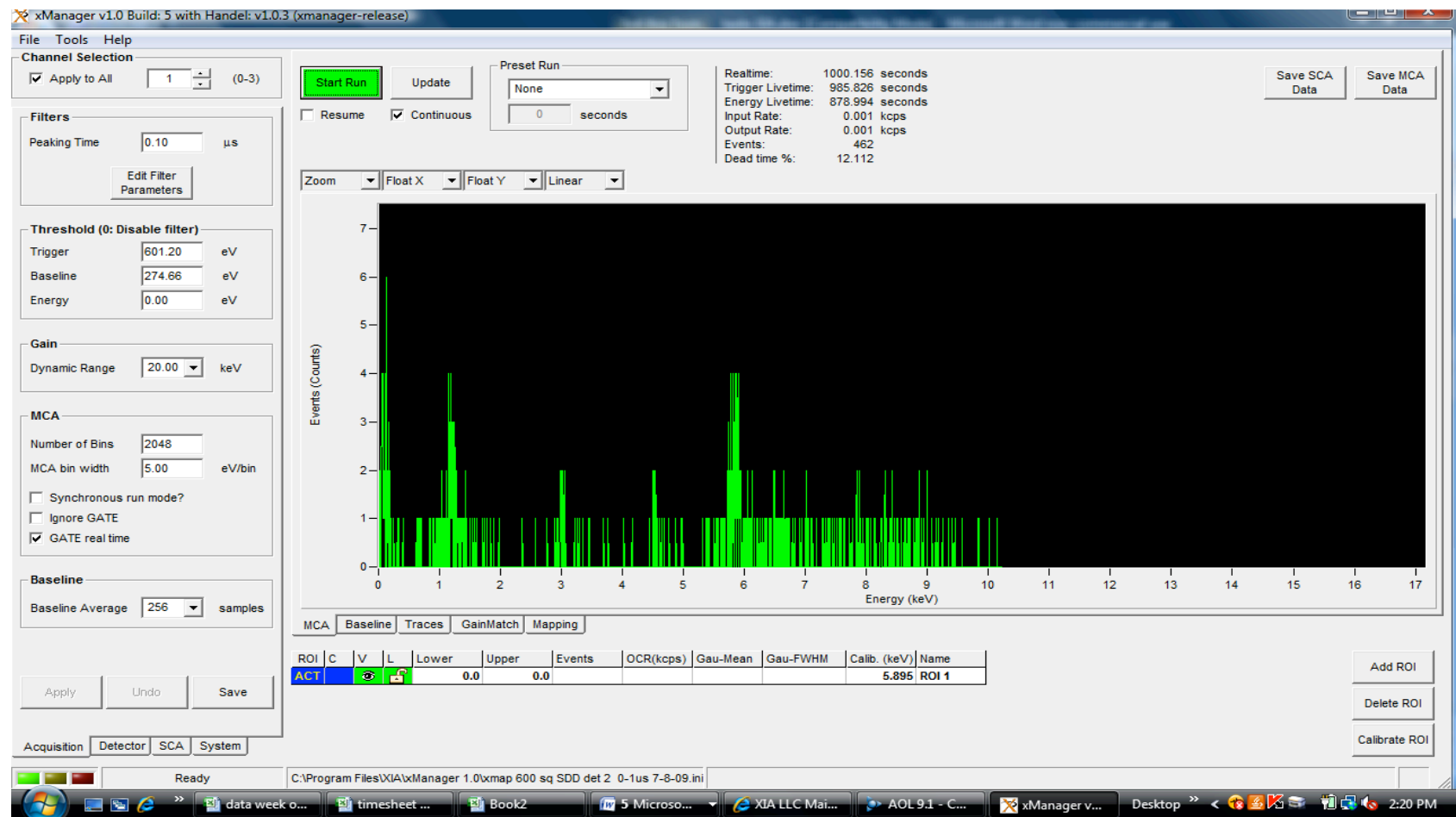

Figure 34. Spectrum from Detector \#2 ch 1 (blanked off) when Detector \#4 irradiated. 